University of Louisville

ThinkIR: The University of Louisville's Institutional Repository

Electronic Theses and Dissertations

1986

\title{
A LORAN-C antenna coupling unit.
}

Timothy Andrew Reilly 1963-

University of Louisville

Follow this and additional works at: https://ir.library.louisville.edu/etd

Part of the Electrical and Computer Engineering Commons

\section{Recommended Citation}

Reilly, Timothy Andrew 1963-, "A LORAN-C antenna coupling unit." (1986). Electronic Theses and Dissertations. Paper 2117.

https://doi.org/10.18297/etd/2117

This Master's Thesis is brought to you for free and open access by ThinkIR: The University of Louisville's Institutional Repository. It has been accepted for inclusion in Electronic Theses and Dissertations by an authorized administrator of ThinkIR: The University of Louisville's Institutional Repository. This title appears here courtesy of the author, who has retained all other copyrights. For more information, please contact thinkir@louisville.edu. 
A LORAN-C ANTENNA COUPLING UNIT

By

Timothy Andrew Reilly

B.S., University of Loüisville, 1986

\author{
A Thesis \\ Submitted to the Faculty of the \\ University of Louisville \\ speed scientific School \\ as Partial Fulfillment of the Requirements \\ for the Professional Degree
}

MASTER OF ENGINEERING

Department of Electrical Engineering

December 1986 
A LORAN-C ANTENNA COUPLING UNIT

Submitted by:

Timothy Andrew Reilly

A Thesis Approved on

JuTy 25,1986

Date

by the Following Reading and Examination Committee:

Thesis Co-Director, Thomas G. Cleaver

Thesis Co-Direetor, Verne E/Baxter

Samuel V. Bell

Dermot J. Collins 


\section{ACKNOWLEDGEMENTS}

The author would like to express thanks to the following people who have given help and support throughout this project: to Professors Verne Baxter and Thomas Cleaver whose guidance and persistence/harassment gave the necessary boost to this project; to Tom Kensky for his expertise in constructing printed circuit boards; to his sisters, Ann and Nancy, for their typing; and to the rest of the family, for their tolerance of the author throughout the course of the project. 


\section{ABSTRACT}

This project is the design of an antenna-coupling unit ( $\mathrm{ACU}$ ) that will operate with the Texas Instruments LORAN-C receiver and a 28-inch antenna. The height of the antenna used at the present is eight feet. Since the application of LORAN-C positioning is being expanded to vehicular location, an eight-foot antenna is not practical. The shorter antenna is necessary to prohibit striking trees, overpasses, etc. The newly designed ACU has more voltage gain to compensate for the attenuation of the incoming signal due to the shortening of the antenna. It also has a bandpass of $90 \mathrm{KHz}-110 \mathrm{KHz}$ with the center frequency being $100 \mathrm{KHz}$, the carrier frequency of LORAN-C, and provides matching between the receiver and the antenna. The new ACU has comparable performance when compared with the TI ACU, but the signal-to-noise ratio is not high enough in many cases. This occurs because low-noise transistors were not us ed. 


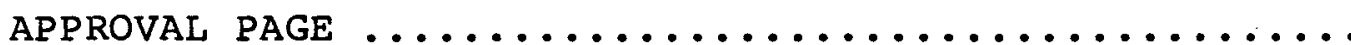

ABSTRACT

TABLE OF CONTENTS

LIST OF TABLES $\ldots \ldots \ldots \ldots \ldots \ldots \ldots \ldots \ldots \ldots \ldots \ldots \ldots \ldots \ldots \ldots$

LIST OF ILLUSTRATIONS $\ldots \ldots \ldots \ldots \ldots \ldots \ldots \ldots \ldots \ldots \ldots \ldots \ldots$

I. INTRODUCTION $\ldots \ldots \ldots \ldots \ldots \ldots \ldots \ldots \ldots \ldots \ldots \ldots$

II. ANALYSIS OF AN ANTENNA-COUPLING UNIT ........ 7

III. PRELIMINARY DESIGN $\ldots \ldots \ldots \ldots \ldots \ldots \ldots \ldots \ldots \ldots$

A. Common Drain Amplifiers .............. 10

B. Common Source Amplifiers ............. 14

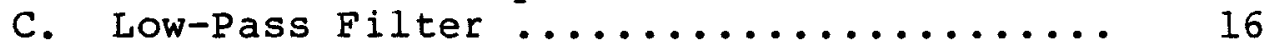

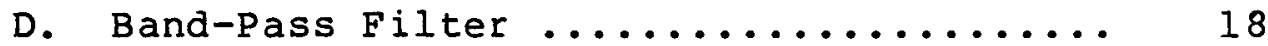

E. Impedance Matching Transformer ........ 20

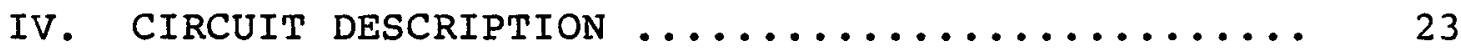

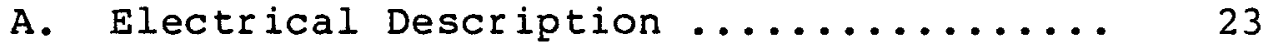

B. Physical Description .............. 27

v. Circuit voltage measurements .............. 30

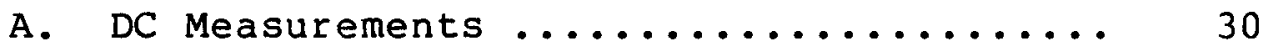

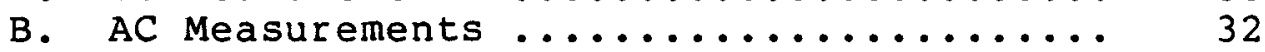

VI. EQUIPMENT OPERATION AND DESCRIPTION ......... 37

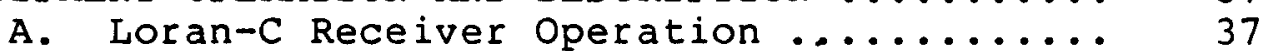

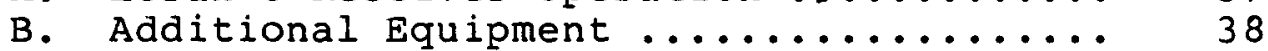

VII. RESULTS OF TESTING .................... 4 I

A. Testing with a Radiating Antenna ....... 41

B. Testing with Loran-C Receiver ......... 43

VIII. DISCUSSION OF RESULTS .................. 54

IX. CONCLUSIONS ....................... 58

REFERENCES ............................... 62

BIBLIOGRAPHY $\ldots \ldots \ldots \ldots \ldots \ldots \ldots \ldots \ldots \ldots \ldots \ldots \ldots \ldots \ldots \ldots \ldots$

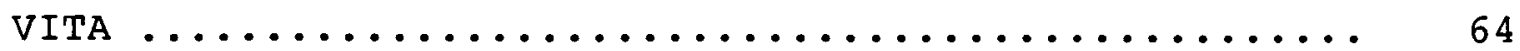




\section{LIST OF TABLES}

TABLE

PAGE

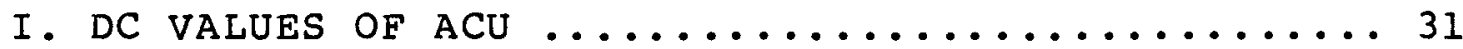

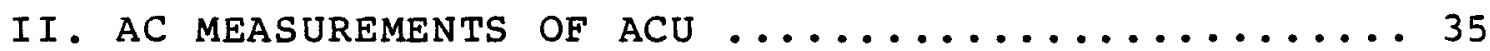

III. DATA WITH ACU OUT OF TUNE .............. 42

IV. DATA WITH RADIATING ANTENNA .............. 44

V. DATA WITH ACU ....................... 48

VI. DATA WITH TI ACU ..................... 49

VII. DATA WITH 28-INCH ANTENNA AND ACU (IN VAN) .... 5I

VIII. DATA WITH EIGHT-FOOT ANTENNA AND TI ACU (IN VAN). 52

IX. DATA WITH BOTH ACUS AND 28-INCH ANTENNA ...... 53 


\section{LIST OF ILLUSTRATIONS}

FIGURE

PAGE

1. LORAN-C Pulse Group ...................... 3

2. LORAN-C Hyperbolic Grid ................... 4

3. Common Drain Amplifier ................... 11

4. Common Source Amplifier ................... 15

5. Low-Pass Filter ........................ 17

6. Band-Pass Filter ........................ 19

7. Impedance Matching Transformer ............. 22

8. Antenna-Coupling Unit (ACU) .................. 24

9. Cable wiring ........................... 29

10. Test set-up ......................... 33

11. ACU with Test Points shown ................ 34

12. Frequency Response of ACU ................ 36

13. Signal-To-Noise Ratio Versus SNR Number ........ 39

14. Frequency Response of ACU ................ 45

15. Frequency Response of $\mathrm{TI}$ ACU ................ 46 


\section{INTRODUCTION}

The Texas Instruments (TI) LORAN-C receivers used presently at the University of Louisville require the use of an eight-foot antenna for proper operation. The antennacoupling unit (ACU) supplied with the TI receiver is designed for optimum use with the eight-foot antenna. It is desired to be able to use the receiver with an antenna of 18 to 28 inches. To accomplish this, the TI ACU would need to be replaced with one with more gain to compensate for the attenuation of the received signal due to the shortening of the antenna. The ACU must also provide stringent filtering outside of the $90 \mathrm{KHz}-110 \mathrm{KHz}$ band and the necessary impedance matching required between the antenna and the LORAN-C receiver.

The LORAN (LOng RAnge Navigation) system evolved from the military's need to find accurately the position of ships and aircraft. The earlier versions of LORAN used frequencies of $1750 \mathrm{KHz}$ to $1950 \mathrm{KHz}$. The range was about 350 miles and had an attainable accuracy of about one mile. 1 In 1959, the LORAN-C system was developed with a carrier frequency of $100 \mathrm{KHz}$. At this lower frequency, groundwave propagation is more efficient and very stable. With the higher stability, high-power transmitters were constructed which increased the range to 1000-1100 miles and also greatly increased the accuracy. 
The position determination is done by using the differences in the time of arrivals of signals from three transmitters: the master, secondary $A$, and secondary $B$. The three transmitters (stations) transmit their signals at precise times. The signal transmitted is a pulsed group. A typical transmission sequence is shown in FIGURE 1. First, the master station transmits a burst of nine pulses with the ninth pulse being used for control and identification purposes. A cesium clock permits the secondary A to wait a precise amount of time after the master station has transmitted and then transmit a group of eight pulses. Secondary $B$ waits a longer interval and transmits its group of eight pulses. These synchronized transmissions make up a LORAN-C pulse group. Each pulse group, or chain, has a unique Group Repetition Interval (GRI). This allows the receiver to identify the LORAN-C chain it is monitoring if it is in an area where coverage overlaps. 2

After having programmed a particular GRI, the LORAN-C receiver in the field receives the LORAN-C pulse group unique to the programmed GRI. When the receiver detects the pulse group, it measures the time difference between the master and secondary $A$ (TDA) and the time difference between the master and secondary $B$ (TDB). The TDA locates the receiver on a hyperbolic line of position. The TDB locates the receiver on an opposing hyperbolic line of position. The intersection of these two lines of position must be the position of the receiver. ${ }^{3}$ FIGURE 2 


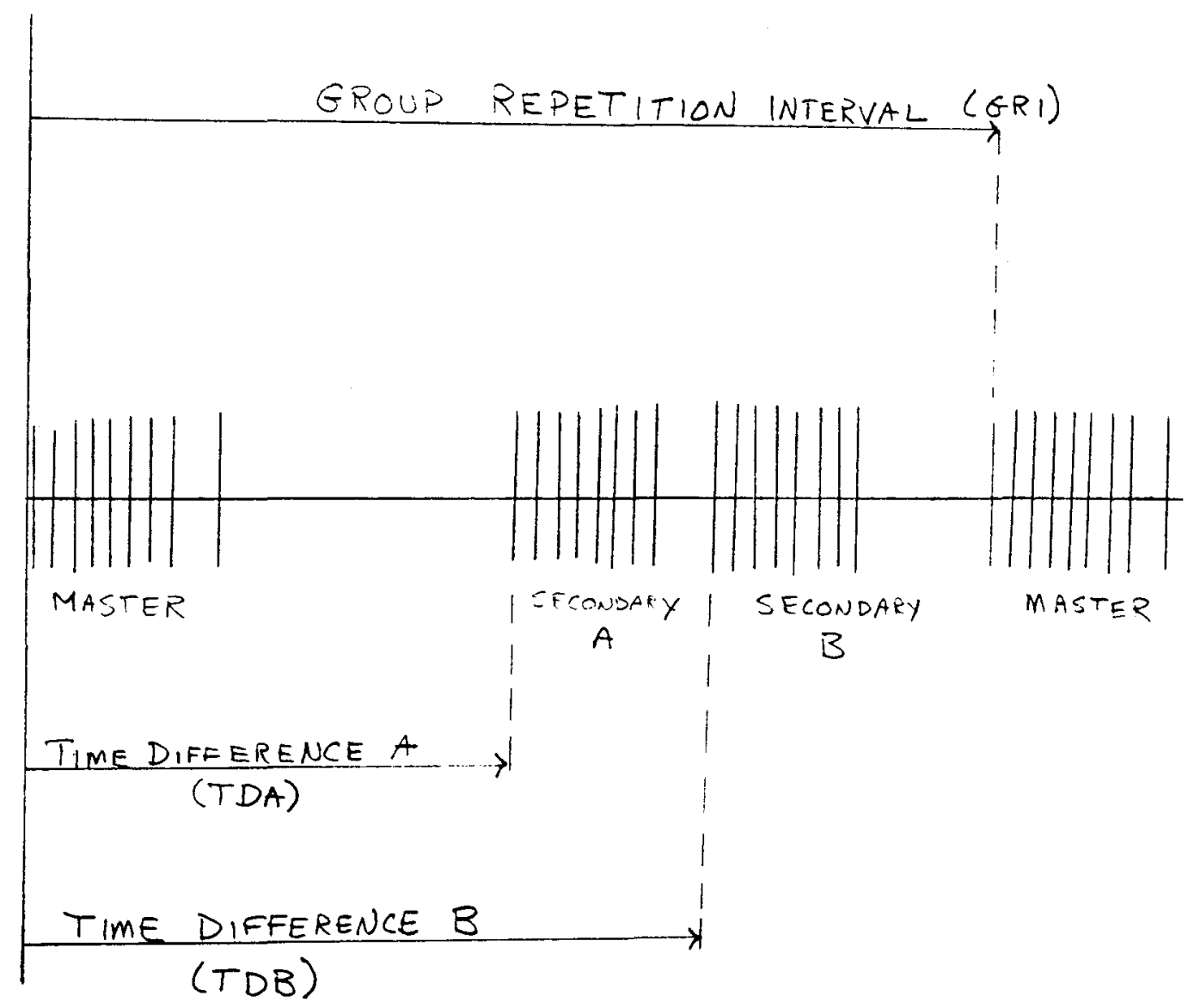

FIGURE 1 - LORAN-C Pulse Group 


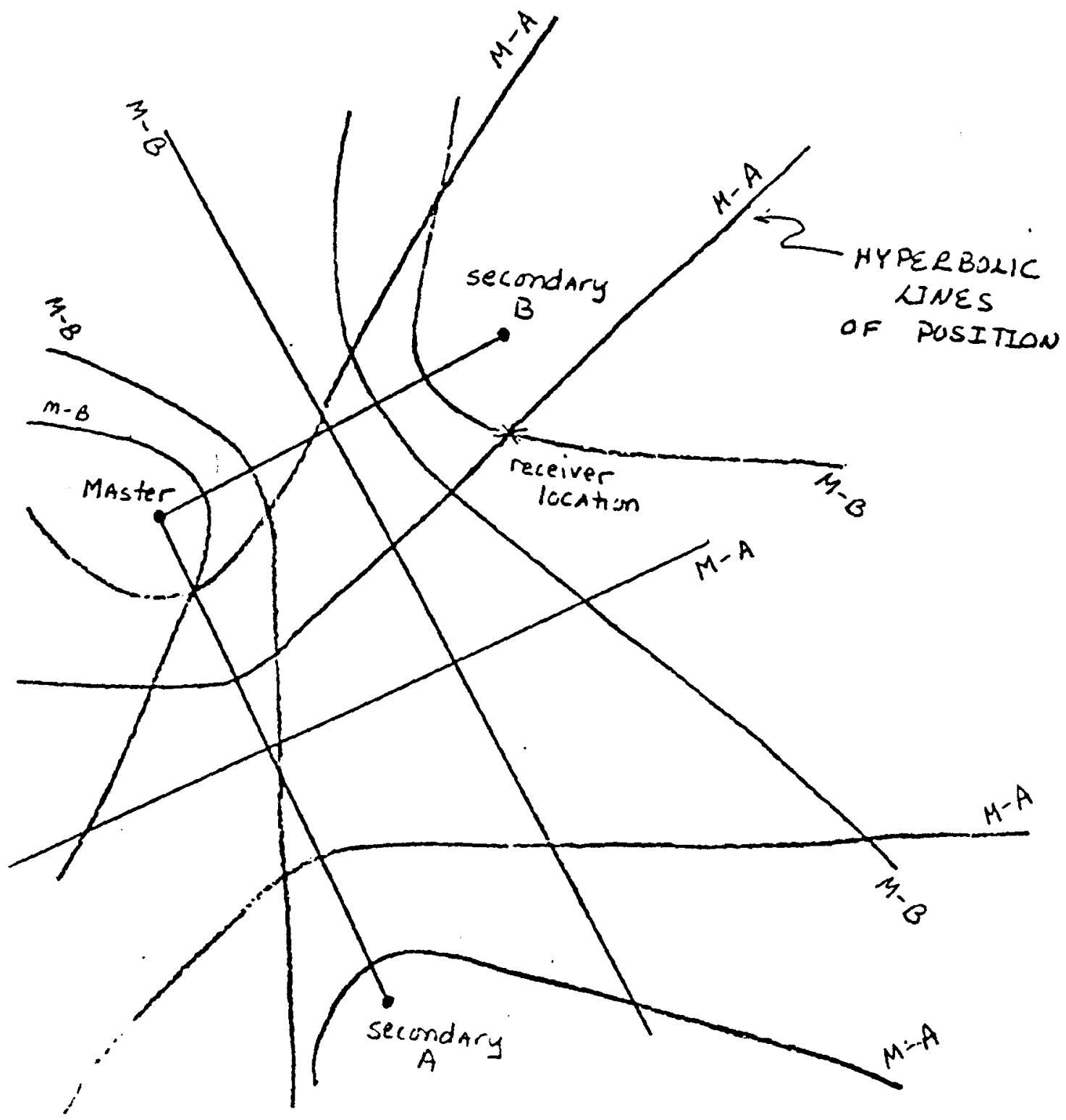

FIGURE 2 - LORAN-C Hyperbolic Grid 
shows these hyperbolic lines of position. LORAN-C charts are available that plot the different time differences and their associated lines of position. The time differences are displayed on the receiver. The operator of the receiver can then locate the unique lines on these charts and obtain the position of the receiver. The process described is not limited to two secondary transmitters. Additional

secondaries just identify additional lines of position.

As for position locating, LORAN-C can be seen to be useful to locate not only ships but also vehicles. An eight-foot antenna presents little problem on a large ship, but when a car has an eight-foot antenna, problems such as the antenna striking an overpass may arise. A shorter antenna is more practical for vehicular use. This is the main reason for this project as LORAN-C use is being expanded to locate vehicles.

The question of feasibility must arise. Realizing that there is an ever present level of Gaussian Atmospheric Noise 4 offers insight into the feasibility of shortening the antenna and obtaining acceptable results. While shortening the antenna will indeed cut down by the same factor the amount of signal received, it also cuts down on the amount of noise picked up by the antenna. This means that if the $A C U$ is low-noise (at least as low in noise as the TI unit), the signal-to-noise ratio with the shorter antenna should be nearly the same as it is with the larger one. Realizing this, one gains confidence that this is, 
indeed, a feasible project. 
II. ANALYSIS OF AN ANTENNA-COUPLING UNIT

The ACU presently used is the one supplied with the Texas Instruments (TI) LORAN-C receiver. It was very difficult to obtain an adequate technical description of the present TI ACU. Technical information from TI was not available. The circuitry of the TI ACU is permanently encapsulated with a potting compound and visual inspection reveals nothing. Also, there was no way of analyzing anything except the output of the unit. Even this was difficult since the only available point to check the output of the unit was inside of the receiver. Because of this, it was virtually impossible to determine the gain of the TI ACU. Many different approaches to measuring the gain of the unit resulted in seemingly contradictory information. It was then decided to design the new ACU with the capability of designing components to adjust the gain of the ACU. A gain of about four times the amount of the TI ACU was desired since the antenna was reduced by about that amount. Subsequent comparative testing of the two units determined if this was accomplished.

The bandpass of the TI ACU was not as elusive. It was stated in the manual that the pass band was from $90 \mathrm{KHz}-110 \mathrm{KHz}$ with a center frequency of $100 \mathrm{KHz}$. Therefore, a bandpass identical to the TI ACU was chosen for the new ACU. 
As can be seen, a clear path was not determined at the outset of this project. This was due mainly to the uncertainty of the necessary gain of the ACU. After a series of trial-and-error designs were made, the one described in the subsequent sections was used. 


\section{PRELIMINARY DESIGN}

The antenna coupling unit (ACU) basically performs four functions. These are antenna matching, signal amplification, signal filtering, and impedance matching to the receiver. Another requirement of the ACU is that it must be very low-noise. When dealing with amplifiers of low level signals in the microvolt range, such as the $A C U$, low-noise is of the utmost concern. For this reason the active device chosen for use in the ACU was the field effect transistor (FET). The FET is less noisy than the bipolar junction transistor (BJT) and is the suitable choice for input stages of low-level amplifiers ${ }^{5}$. The antenna matching is accomplished by the use of a high input impedance amplifier to match the high impedance antenna. This amplifier uses a low-noise FET connected in the common drain configuration. Signal amplification is done by connecting the FET in the common source configuration. The signal filtering is performed by a passive low pass filter and a passive band-pass filter. The impedance matching to the receiver is achieved by a low output impedance common drain FET amplifier that feeds an impedance matching transformer. This transformer couples the signal to an identical transformer at the front end of the receiver. 


\section{A. Common Drain Amplifiers}

When an FET is connected in the common drain configuration, it can be viewed as a buffer. This is because of its high input impedance, low output impedance, and gain of slightly less than one. These characteristics make this configuration the suitable choice to match the antenna, as high impedance is necessary. ${ }^{6}$ The low output impedance will help prevent loading be the following stage. These same characteristics also make the common drain amplifier ideal as the output amplifier because the low output impedance is desirable to drive the impedance matching transformer.

The basic configuration used is shown in FIGURE 3 (a). The FET used is the ECG456 which was listed in the Peeriess Electronics catalogue as the replacement for the Motorola 2N4220. The 2N4220 transistor was chosen mainly because of its low-noise feature. (It was discovered that the replacement was not low-noise, but merely a general purpose FET. This was not realized until very late in the project and will be discussed more in the CONCLUSIONS.) The transistor is a JFET, N-channel, depletion mode type. The electrical characteristics of the ECG456 are as follows:

$$
\begin{aligned}
& \mathrm{v}_{\mathrm{p}}=\mathrm{V}_{\mathrm{gs}} \text { (off) }=-.4 \mathrm{~V} \\
& \mathrm{~V}_{\mathrm{gs}}=-.5 \text { to }-2.5 \mathrm{~V} \\
& \mathrm{I}_{\mathrm{dss}}=3 \mathrm{ma} \\
& \mathrm{g}_{\mathrm{m}}=1000 \text { to } 4000 \mathrm{us}
\end{aligned}
$$




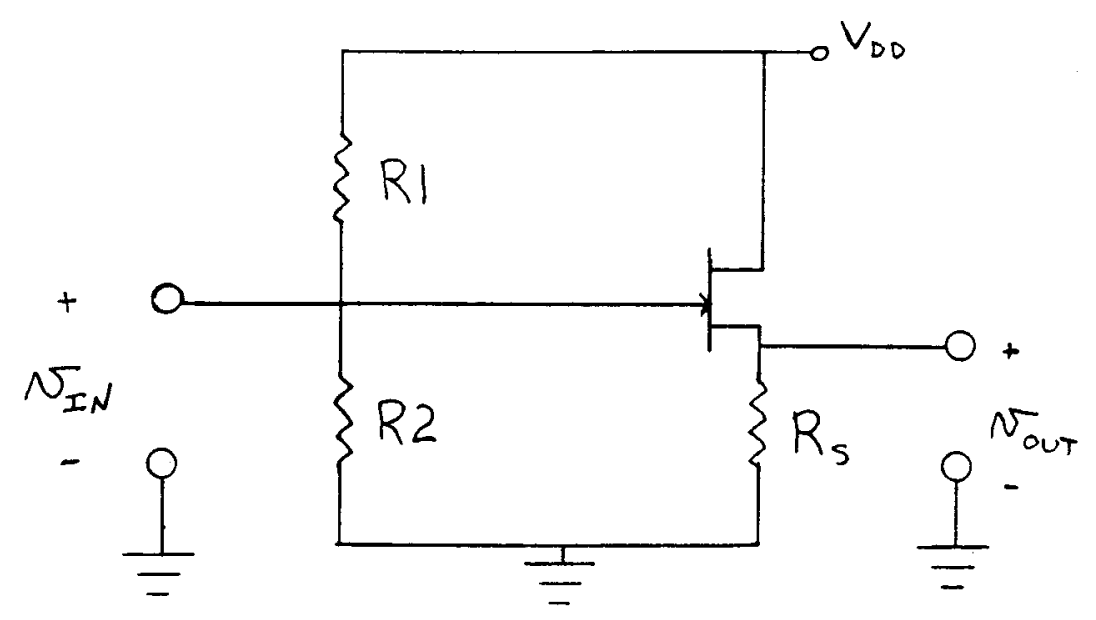

(a)

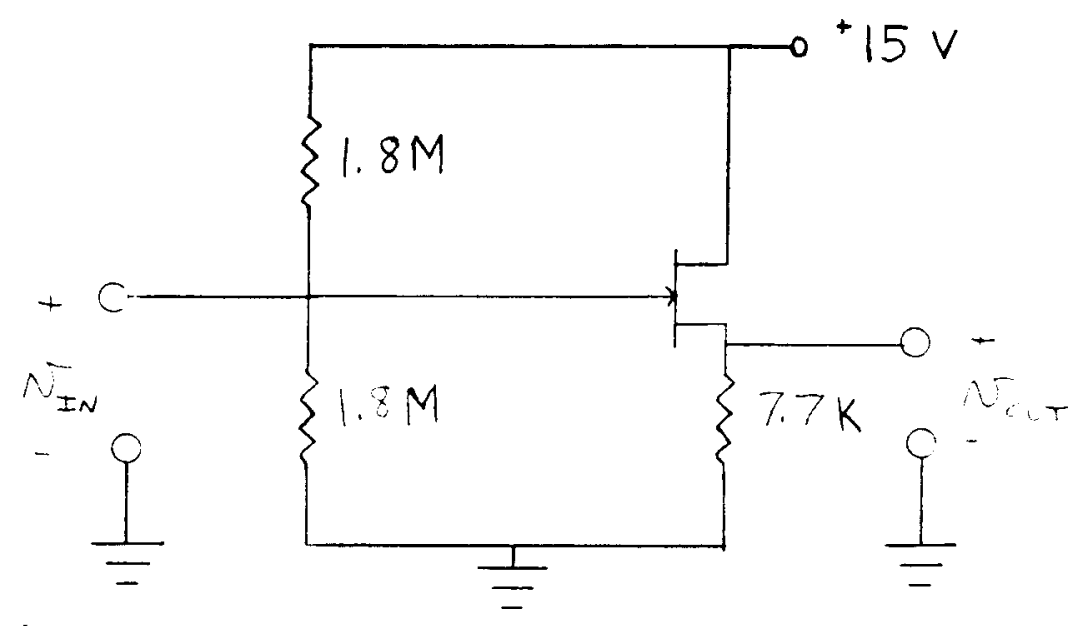

(b)

FIGURE 3 - Common Drain Amplifier 
$\mathrm{V}_{\mathrm{gs}}$ chosen for this circuit was $-1.5 \mathrm{~V}$. By designing for a $V_{g s}$ of $-1.5 \mathrm{~V}$, the current $I_{d q}$ is low and this keeps the noise very low. I $\mathrm{dq}$, the current at the Q-point, can now be determined by the following equation:

$$
\begin{aligned}
& I_{d q}=I_{d s s}\left(1-\left(V_{g s} / V_{p}\right)\right)^{2} \\
& I_{d q}=3 \mathrm{ma}(1-(-1.5 /-4))^{2} \\
& I_{d q}=1.17 \mathrm{ma} .
\end{aligned}
$$

The $v_{d d}$ of the circuit is $15 \mathrm{~V}$. This is the voltage level supplied by the TI LORAN-C receiver to the antenna coupling unit. The circuit was designed for a $v_{d s}$ of $6 \mathrm{~V}$. This value was used to obtain a bias voltage $\mathrm{V}_{\mathrm{ds}}$ about midway in the range $0-15 \mathrm{~V}$. With $\mathrm{v}_{\mathrm{ds}}=6 \mathrm{~V}, \mathrm{v}_{\mathrm{s}}=9 \mathrm{~V}$, the source resistor, $\mathrm{R}_{\mathrm{S}}$, was found by

$$
\begin{aligned}
& \mathrm{R}_{\mathrm{S}}=\mathrm{V}_{\mathrm{s}} / \mathrm{I}_{\mathrm{dq}} \\
& \mathrm{R}_{\mathrm{S}}=9 \mathrm{~V} / 1.17 \mathrm{ma} \\
& \mathrm{R}_{\mathrm{S}}=7.7 \mathrm{~K} \Omega .
\end{aligned}
$$

The two bias resistors, R1 and R2, were determined by assuming a voltage, $\mathrm{v}_{g}$, of $7.5 \mathrm{~V}$ at the gate. This voltage was used because of the $v_{g s}$ used for the circuit. Since $\mathrm{V}_{\mathrm{gs}}=-1.5 \mathrm{~V}$ and $\mathrm{V}_{\mathrm{s}}=9 \mathrm{~V}$, the voltage at the gate must be $1.5 \mathrm{~V}$ lower than the source. Therefore, if $\mathrm{V}_{\mathrm{S}}=9 \mathrm{~V}$ and $\mathrm{v}_{\mathrm{gs}}=-1.5 \mathrm{~V}, \mathrm{v}_{\mathrm{g}}$ needs to be $7.5 \mathrm{~V}$. The two bias 
resistors serve as a voltage divider. The ratio can be found as follows:

$$
V_{d d}(R 2 /(R l+R 2))=V_{g} \text {. }
$$

With $v_{d d}=15 \mathrm{~V}$ and $v_{g}=7.5 \mathrm{~V}$, the ratio of $\mathrm{R} 1 / \mathrm{R} 2$ becomes one. RI and R2 were chosen as $1.8 \mathrm{M} \Omega$ to have high input impedance to the amplifier. The input impedance is given by

$$
\begin{aligned}
& R_{i}=R 1 \| \mathrm{R} 2 \\
& R_{i}=1.8 \mathrm{M} \Omega|| 1.8 \mathrm{M} \Omega \\
& R_{i}=900 \mathrm{k} \Omega
\end{aligned}
$$

The voltage gain, $A_{V}$, of this circuit is given by

$$
A_{v}=\frac{V_{O}}{V_{i}}=\frac{g_{m} * R_{s}}{1+g_{m} * R_{s}}=\frac{R_{S}}{{ }{ }_{s}+R_{s}}
$$

where ${ }^{\prime} s$ ' the AC resistance seen looking back into the JFET, is given by

$$
r_{s}=1 / g_{m}
$$

The experimental value of $g_{m}$ was determined to be 2000 us. (This was done by constructing a common source amplifier, determining the gain, and then finding $g_{m}$ by (7).) This 
is the value of $g_{m}$ that will be used in all calculations. With $R_{S}=7.7 \mathrm{~K}$ and $r_{S}=.500 \mathrm{~K}$, the voltage gain is 0.93. There is no change in polarity of the signal. The circuit with component values is shown in FIGURE $3 \mathrm{~b}$. The output resistance, $R_{O^{\prime}}$ of a common drain amplifier is the parallel combination of the source resistance, $R_{S^{\prime}}$ and the $A C$ resistance, $r_{S}$.

$$
\begin{aligned}
& R_{0}=R_{s} \| r_{s} \\
& R_{0}=(.5 \mathrm{~K})||(7.7 \mathrm{~K}) \\
& R_{0}=470 \Omega
\end{aligned}
$$

This circuit was used twice in the design; once at the input from the antenna and again at the output to drive the transformer.

\section{B. Common Source Amplifiers}

To achieve the necessary gain for the ACU, two JFE'T amplifiers connected in the common source configuration were used. The basic configuration used is shown in FIGURE 4 . Using the transistor described in the previous section, the circuit was designed for a voltage gain of ten. $V_{g s}$ was chosen to be $-1 \mathrm{~V}$. This value was chosen to minimize noise. With $I_{\text {dss }}=3 \mathrm{ma}$ and $\mathrm{V}_{\mathrm{p}}=-4 \mathrm{~V}, \mathrm{I}_{\mathrm{dq}}$ can be found by equation (1) to be $1.69 \mathrm{ma}$. To obtain a $V_{d q}$ about midway in the range of $0-15 \mathrm{~V}$, a $\mathrm{V}_{\mathrm{dq}}$ of $9 \mathrm{~V}$ was the design value used. This $9 \mathrm{~V}$ value was split up with $\mathrm{V}_{\mathrm{ds}}=7 \mathrm{~V}$ 


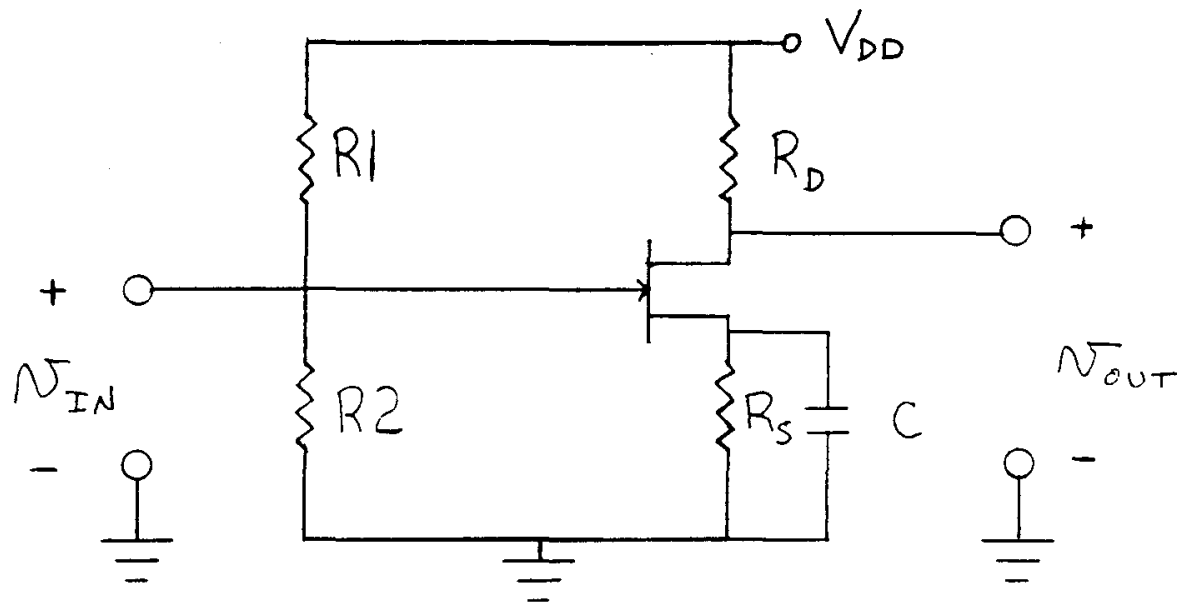

FIGURE 4 - Common Source Amplifier 
and $v_{S}=2 \mathrm{~V}$. The remaining six volts of the 15 volt $V_{d d}$ was used for the voltage across $R_{d}$. With these values, $R_{S}$ can be determined by equation (2) and found to be approximately $1.2 \mathrm{k} \Omega . \mathrm{R}_{\mathrm{d}}$ is found by

$$
A_{v}=-g_{m} * R_{d}
$$

For a gain of at least 10 and $g_{m}$ of 2000 uS, $R_{d}$ should be $6.2 \mathrm{k} \Omega$. The negative sign indicates a phase shift of 180 degrees.

Since $\mathrm{v}_{\mathrm{gs}}=-1 \mathrm{~V}$ and $\mathrm{v}_{\mathrm{s}}=2 \mathrm{~V}, \mathrm{v}_{\mathrm{g}}$ should be $\mathrm{I} \mathrm{V}$. Using (3) with $\mathrm{v}_{\mathrm{g}}=1 \mathrm{~V}$ and $\mathrm{v}_{\mathrm{dd}}=15 \mathrm{~V}, \mathrm{R} 1 / \mathrm{R} 2$ becomes 14. This is the ratio used for the common source circuits. Depending on the circuitry that precedes the common source stages, RI and R2 will be chosen accordingly.

\section{Low-Pass Filter}

A second order low pass filter was employed to attenuate signals with frequencies above $200 \mathrm{kHz}$. The lowpass configuration is shown in FIGURE 5 . The transfer function for this filter is

$$
\frac{v_{O}}{v_{i}}=\frac{1 /\left(L^{*} C\right)}{s^{2}+s *\left(1 /\left(R^{*} C\right)\right)+1 /\left(L^{*} C\right)}
$$




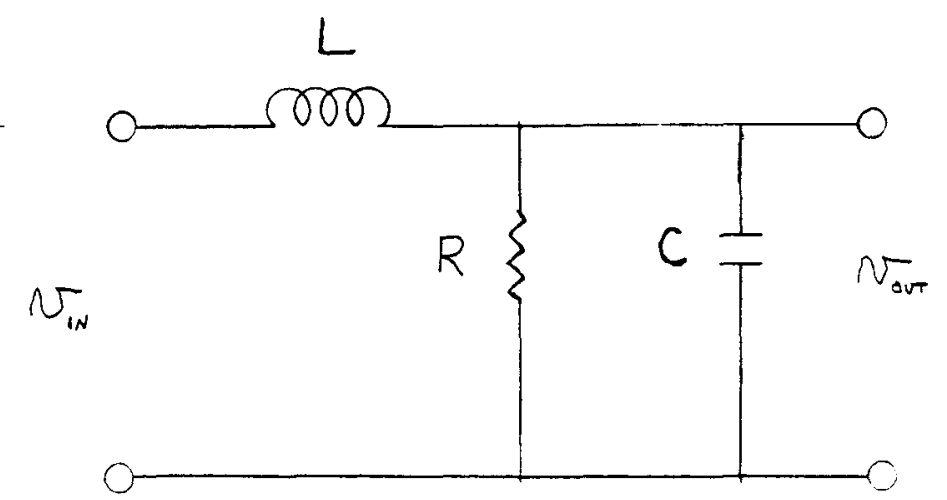

FIGURE 5 - Low-Pass Filter 
This yields the parameters

$$
\begin{gathered}
w_{0}=\frac{1}{\sqrt{L^{* C}}} \\
Q=R * \sqrt{(C / L)} .
\end{gathered}
$$

For an $w_{0}$ of $2 \pi *(200 \mathrm{KHz})$ and a $Q$ of 1 , the component values are found to be

$$
\begin{aligned}
& L=10 \mathrm{mH} \\
& C=64 \mathrm{pF} \\
& R=12.6 \mathrm{k \Omega} .
\end{aligned}
$$

$200 \mathrm{KHz}$ was chosen because it was high enough, above $100 \mathrm{KHz}$, to not affect the $100 \mathrm{KHz}$ signal. The $Q$ of 1 was chosen for minimum ripple in the passband while maintaining a high value for $R$. This is necessary to minimize loading. The $w_{0}$ of $2 \pi^{*} 200 \mathrm{kHz}$ is not a critical value; therefore, it was not necessary to use components exactly as calculated.

\section{Band-Pass Filter}

To achieve the necessary band pass of $90 \mathrm{KHz}-110 \mathrm{KHz}$, a passive second order band-pass filter was used. The circuit used is shown in FIGURE 6. The transfer function is 


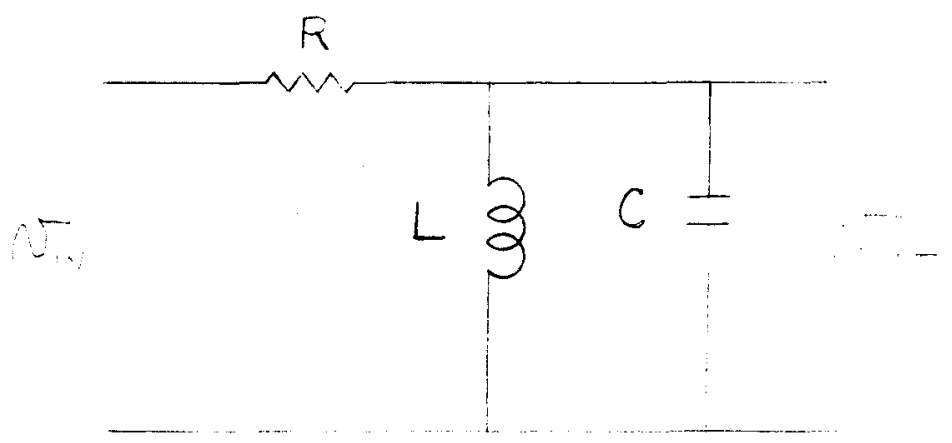

FIGURE 6 - Band-Pass Filter 


$$
-\mathrm{V}_{\mathrm{O}_{-}}=\frac{\mathrm{s}^{*}\left(1 /\left(\mathrm{R}^{*} \mathrm{C}\right)\right)}{\mathrm{V}_{\mathrm{i}}}=\frac{\bar{s}^{2}+\mathrm{s}^{*}\left(1 /\left(\mathrm{R}^{*} \mathrm{C}\right)\right)+1 /\left(\mathrm{L}^{*} \mathrm{C}\right)}{}
$$

From this transfer function, the bandwidth, BW, and the center frequency, $w_{0}$, for the circuit are

$$
\begin{gathered}
B W=\frac{1}{R^{*} C} \\
w_{0}=\frac{1}{\sqrt{L^{*} C}} .
\end{gathered}
$$

The $w_{0}$ chosen for the filter is $2 * 100 \mathrm{KHz}$ and the $\mathrm{BW}$ is $2 \pi * 20 \mathrm{kHz}$. This yields

$$
\begin{aligned}
& \mathrm{L}=10 \mathrm{mH} \\
& \mathrm{C}=253 \mathrm{pF} \\
& \mathrm{R}=31 \mathrm{k} \Omega .
\end{aligned}
$$

These values may need to be adjusted to tune the circuit to a center frequency of $100 \mathrm{kHz}$. The output resistance of the stage before the band pass filter is taken into account when choosing $R$ and is discussed later.

\section{E. Impedance Matching Transformer}

The impedance matching transformer used is the identical part used in the TI ACU. No printed specifications on this transformer could be found. The part is connected at the output of the second common drain 
circuit. The transformer was measured to have a $4: 1$ voltage ratio and is used to drive the $600 \Omega$ cable and match to an identical transformer at the front end of the receiver. A capacitor is put across the input to tune the transformer to $100 \mathrm{KHz}$. The pinout of the part and the connections to the circuit are shown in FIGURE 7 . 


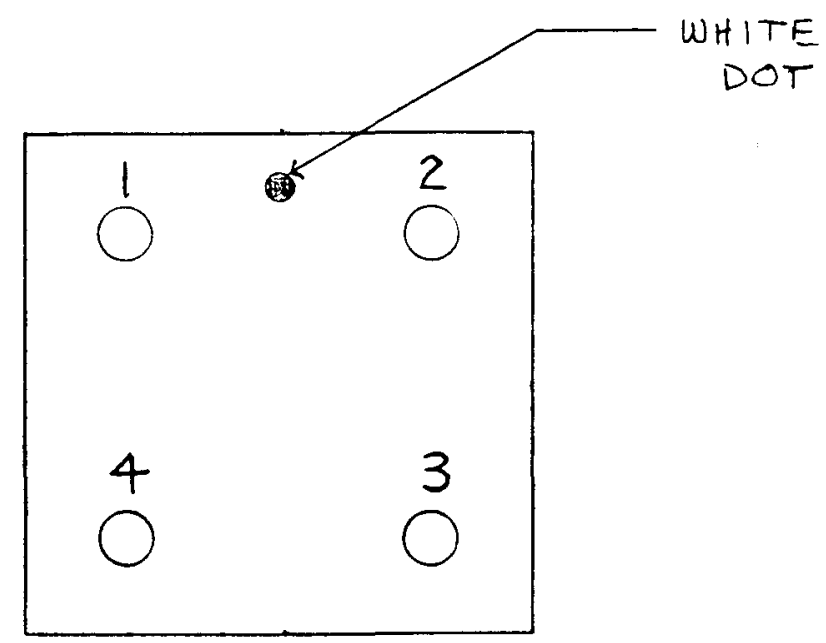

(a)

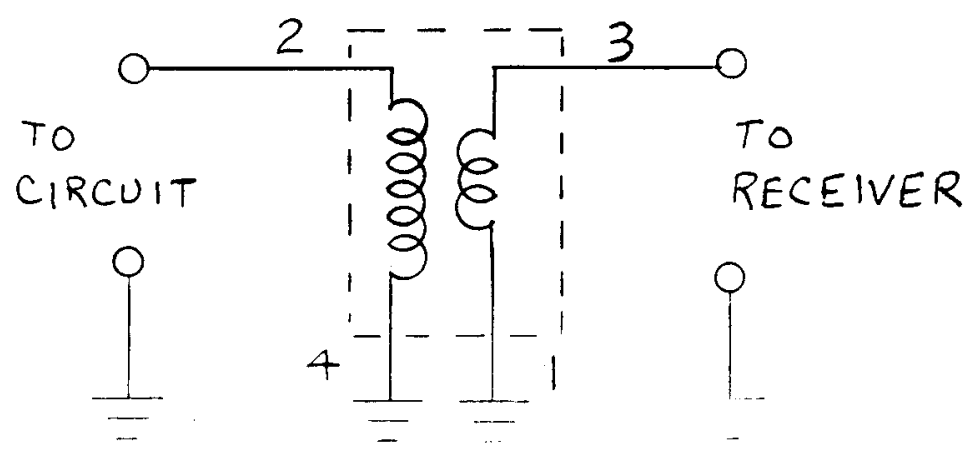

(b)

FIGURE 7 - Impedance Matching Transformer 


\section{CIRCUIT DESCRIPTION}

\section{A. Electrical Description}

The basic stages of the overall circuit were discussed in Chapter III. Using these as building blocks, the author constructed the circuit, shown in FIGURE 8. RI, R2, R3, and $Q 1$ make up the first common drain circuit. The component values of $\mathrm{Rl}=\mathrm{R} 2=1.8 \mathrm{M} \Omega$ and $\mathrm{R} 3=7.7 \mathrm{~K} \Omega$ were determined in Chapter III. Cl functions as a DC block and isolates the stages, as does $\mathrm{C} 3, \mathrm{C} 6, \mathrm{C} 8$, and $\mathrm{Cl0}$. The value chosen was .01 UF. This value was chosen because it functioned well as a DC block and also had little effect on the filtering action of the band-pass and low-pass filters. Subsequent calculations showed the cut-off frequencies of the capacitors to range from $200 \mathrm{~Hz}$ to $400 \mathrm{~Hz}$, thus verifying that the capacitors served well as a DC block. The low-pass filter is composed of LI, C2, and the parallel combination of $\mathrm{R} 4$ and $\mathrm{R} 5$. Since the resistance for the low pass filter was calculated in Chapter III to be approximately $12.6 \mathrm{~K} \Omega$, $\mathrm{R} 4$ was chosen as $180 \mathrm{~K} \Omega$ and $\mathrm{R} 5$ was chosen as $13.3 \mathrm{~K}$. The parallel combination of these resistors yields a value of $12.4 \mathrm{~K} \Omega$, which is close to the desired value of $12.6 \mathrm{k} \Omega$. The combination of $\mathrm{R} 4$ and $\mathrm{R} 5$ must also yield a ratio of $\mathrm{R} 4 / \mathrm{R} 5=14$ to achieve the desired gate voltage of one volt on Q2. With the values chosen, this criterion is also satisfied. Ll was calculated to be $10 \mathrm{mH}$ 


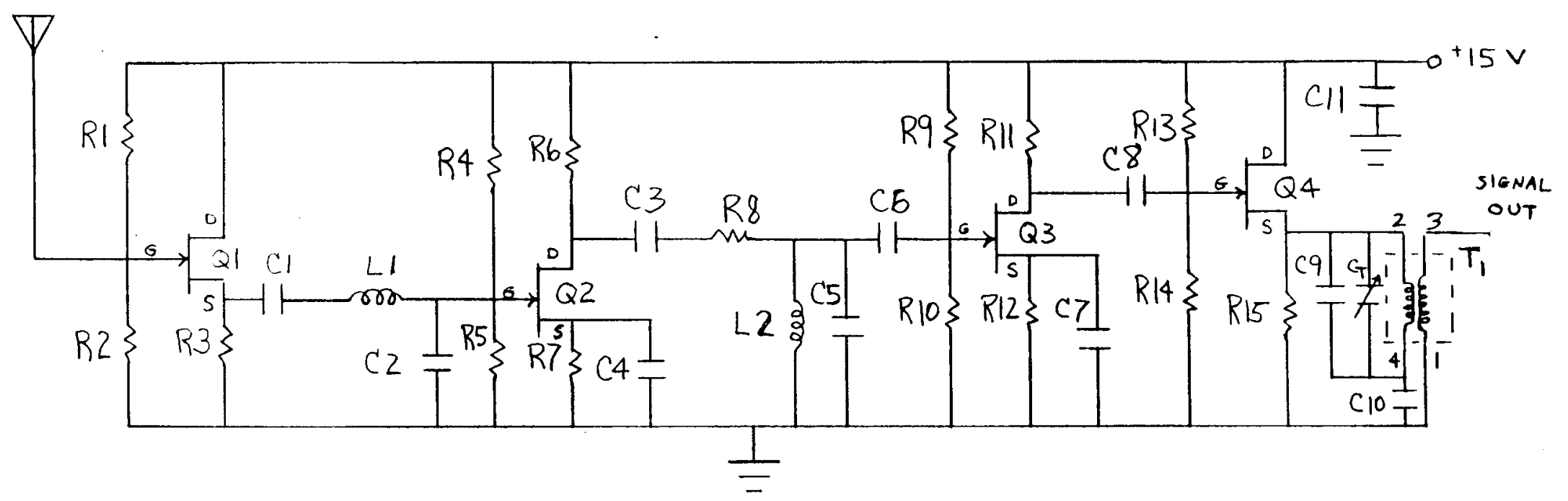

$$
\begin{aligned}
& \therefore 1=R-F 9=R 13=R 14=1.8 \mathrm{~m} \Omega \quad C_{1}=C 3=C 6=C 8=C 10=.01 \mu F \quad L 1=\angle 2=10 \mathrm{mH} \\
& R 3=R 15=7.7 \mathrm{~K} \Omega \quad C 2=63 \mathrm{pF} \\
& R 4=186 K \Omega \quad C 4=C 7=.033 \mu \mathrm{F} \\
& R F=13.3 \mathrm{~K} \Omega \quad C 5=253 \mathrm{pF} \\
& R 6=P_{1} 11=6.2 \mathrm{~K} \Omega \quad C 9=100 \mathrm{PF} \\
& R 7=R_{12}=1.2 \mathrm{~K} \Omega \quad C 11=1, \mu \mathrm{F} \\
& R Q=\cdots K R \quad C T=15-150 \mathrm{pF} \\
& P_{10}=12 C K \Omega \quad Q 1=Q 2=Q 3=Q 4=E C G 456
\end{aligned}
$$

FIGURE 8 - Antenna Coupling Unit (ACU) 
and $\mathrm{C} 2$ was found to be $63 \mathrm{pF}$ as developed in Chapter III. The next stage is the first common source stage. Voltage gain is the function of this stage. R4 and R5 have been discussed. $\mathrm{R} 6$ and $\mathrm{R} 7$ were chosen as $6.2 \mathrm{~K} \Omega$ and $1.2 \mathrm{~K} \Omega$, respectively, as determined in Chapter III. C4 was chosen so that its reactance, $x_{C^{\prime}}$ at $100 \mathrm{KHz}$ was at least 20 times less than the source resistor, Rs for $R 7$ in this case), of $1.2 \mathrm{k} \Omega$. By choosing $C 4$ to have a value $.033 \mathrm{uF}$, the $x_{c}$ is

$$
\begin{aligned}
& x_{c}=\frac{1}{2 \pi * f * C}, \\
& x_{C}=24 . \Omega .
\end{aligned}
$$

The purpose of $\mathrm{C} 4$ is to provide a good $\mathrm{AC}$ short to ground. A capacitor across the source resistor also increases the gain appreciably. Without the capacitor, the gain is found by

$$
A_{v}=\frac{-g_{m} * R_{d}}{1+g_{m} * R_{s}}
$$

By having $R_{S}$ effectively shorted by a capacitor, the $R_{S}$ in (15) drops out and the gain equation becomes

$$
A_{v}=-g_{m} * R_{d}
$$


By comparing (15) and (16), the gain of (16) will always be much larger. The circuit was designed for a gain of ten. The output resistance, $R_{\circ}$, of the common source amplifier is given by

$$
R_{0}=R_{d} \cdot
$$

$R_{d}$ is the resistor in the drain and is $R 6=6.2 \mathrm{~K}$. This value of $R_{0}$ is incorporated with the resistance necessary in the band-pass filter, which is the next stage to be discussed.

The band-pass filter necessary in the ACU is made up of Ro of the previous stage, R8, L2, and C5. The resistance, inductance, and capacitance needed in the band pass filter were determined in Chapter III. The resistance was calculated to be $31 \mathrm{~K}$. The series combination of Ro and R8 were chosen to make up this resistance. Since $R_{0}=R_{d}=6.2 \mathrm{~K} \Omega, R 8$ was chosen to be $25 \mathrm{~K} n$. The addition of $R_{0}$ and $R 8$ equals the desired $31 \mathrm{~K} \Omega$ resistance. L2 and $\mathrm{C} 5$ are $10 \mathrm{mH}$ and $253 \mathrm{pF}$ respectively.

The combination of R9, Rl0, RlI, Rl2, C6, and Q3 makes up the second of two voltage-gain common source stages. R9 and Rlo were made large to prevent loading of the previous stage and eliminate affecting the performance of the band pass filter. The ratio of $R 9 / R 10=14$ was also needed to achieve the gate voltage of one volt. Based on these criteria, R9 was chosen as 1.8 Mand R10 was chosen as 
$130 \mathrm{~K}$. Rl1, Rl2, $\mathrm{C7}$, and $\mathrm{C} 8$ are respectively identical to R6, R7, C4, and C3 and were selected for the reasons discussed previously.

The second common drain circuit, composed of R13, R14, R15, and Q4, is identical to the first common drain circuit. The low output resistance of approximately 500 was essential in driving the output transformer.

The output transformer is a tuned transformer. By experimentally placing capacitors across the terminals two and four, the transformer was tuned to peak at $100 \mathrm{KHz}$. BY itself, the transformer was tuned with a capacitance of $180 \mathrm{pF}$. To compensate for any additional capacitance encountered when inserting the transformer in the actual circuit, a fixed capacitor of $100 \mathrm{pF}$ and a trimmer capacitor of 15-150 pF were put in parallel across pins two and four of the transformer. This allowed for fine tuning when the circuit was constructed. $\mathrm{Cll}$ is the combination of several capacitors in parallel from the power supply to ground. These capacitors are placed in several places throughout the board as decoupling capacitors and have values of .01 uF and $1 \mathrm{uF}$.

\section{B. Physical Description}

The antenna-coupling unit is comprised of a printed circuit board with components mounted inside an aluminum box of dimensions $51 / 4 " \times 3 " \times 2$ ". The PC board measures $37 / 8 " \times 25 / 8 "$. The PC board and box are mounted on a 
metal plate 9 " $51 / 4$ " which has a large magnet connected on the bottom. This allows the unit to be placed on top of the car and remain in place. Mounted on the metal plate, but insulated from the plate, is the mounting socket for the antenna. The thread size of the mounting socket is 3/8 inch by 24. A wire leads from the mounting socket into a hole in the aluminum box. This wire is connected to the input of the circuit.

On the side opposite the hole used for the antenna wire, is a rectangular opening. Inserted in this is the cable that connects to the LORAN-C receiver. The cable has a connector at one end with seven pins to which are connected the wires in the cable. The wires are soldered directly to a female type 16 pin connector. This connector is then plugged into the 16 pin connector fixed on the PC board. This type of construction allowed easy adjustments to the $A C U$ as the cable was easily removed. At the other end of the cable is a round-plug connector that is plugged into the back of the LORAN-C receiver. The cable wiring is shown in FIGURE 9. 
29

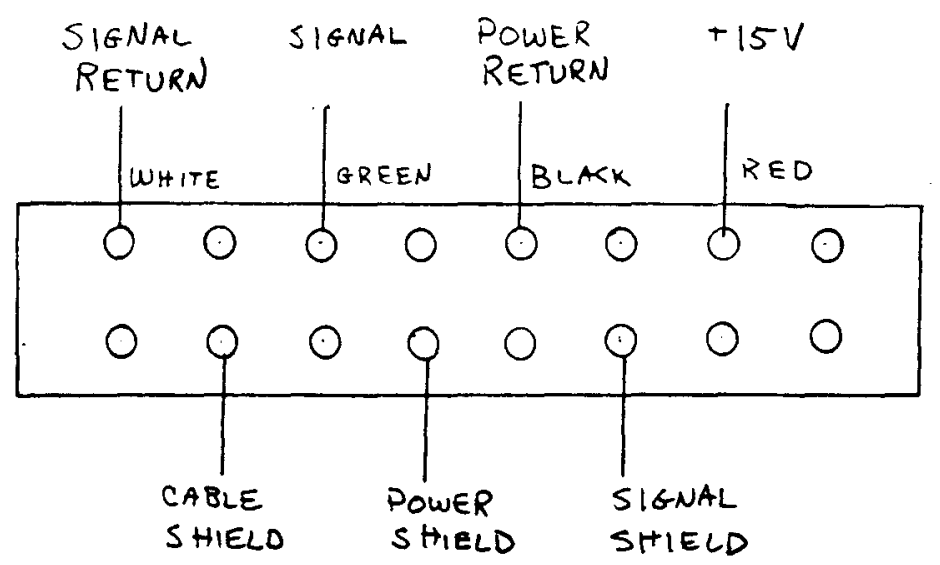

CONNECTOR AT AC END (FRONT VIEW)

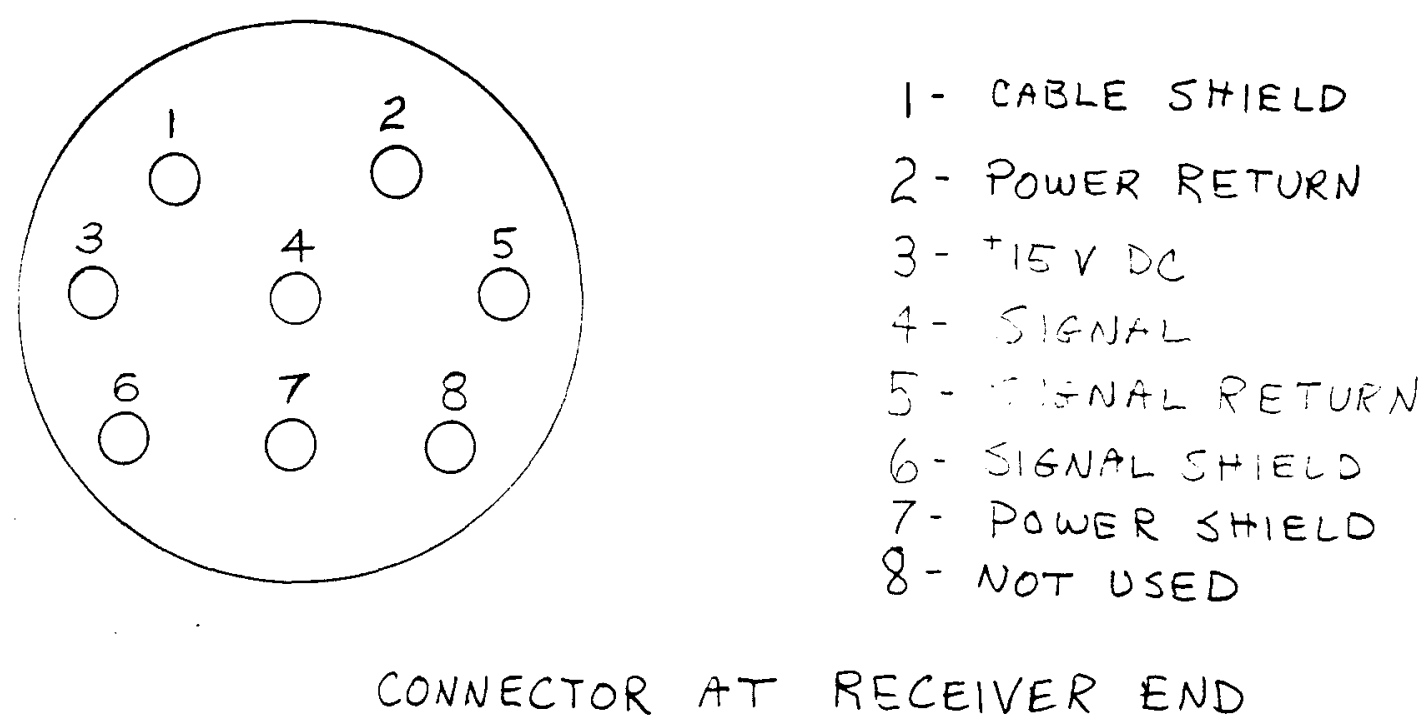

FIGURE 9 - Cable Wiring 


\section{CIRCUIT VOLTAGE MEASUREMENTS}

\section{A. DC Measurements}

The circuit was constructed and the necessary DC measurements were taken. These measurements, along with the desired values, are presented in TABLE I. The letters under the heading "TP" (for Test Point) signify the point at which the voltage was measured. The convention used was as follows: VGl is the voltage at the gate of the first transistor. VSI is the voltage at the source of the first transistor. VD2 is the voltage at the drain of the second transistor, and so on. While the desired values and measured values do not exactly match, the design was not changed. It is impossible to try to achieve exact results when one is dealing with components with tolerances such as resistors, and transistors that have specifications that range from a minimum to a maximum. Therefore, if the measured values are relatively close to the desired values, the design is acceptable and will function very nearly the same as if the values were identical. Another factor that contributed to the difference in the desired and measured values was because the transistor used was not the part the circuit was designed for. This is discussed more in the conclusions along with possible problems the discrepancies may cause. 
TABLE I

DC VALUES

\begin{tabular}{|c|c|c|}
\hline TP & DESIRED & MEASURED \\
\hline VG 1 & $7.5 v$ & $6.8 \mathrm{~V}$ \\
\hline VS1 & $9.0 \mathrm{~V}$ & $8.4 \mathrm{~V}$ \\
\hline VGE & $1.0 \mathrm{~V}$ & $1.0 \mathrm{~V}$ \\
\hline vS2 & $2.0 \mathrm{~V}$ & $1.8 v$ \\
\hline VDE & $9.0 \mathrm{~V}$ & $5.6 \mathrm{~V}$ \\
\hline VG3 & $1.0 \mathrm{~V}$ & $.9 \mathrm{~V}$ \\
\hline V53 & $2.0 \mathrm{~V}$ & $1.7 \mathrm{~V}$ \\
\hline VD3 & $9.0 \mathrm{~V}$ & $6.1 \mathrm{~V}$ \\
\hline VG4 & $7.5 \mathrm{~V}$ & $6.5 \mathrm{~V}$ \\
\hline VS4 & $9.0 \mathrm{~V}$ & $8.0 \mathrm{~V}$ \\
\hline
\end{tabular}




\section{B. AC Measurements}

Using a Wavetek function generator, a low-level sine wave was input to the circuit. A $35 \mathrm{pF}$ capacitor was placed in series with the wavetek to AC couple the generator to the ACU. The test set-up is shown in FIGURE 10.

Voltage measurements were taken at the points shown in FIGURE 11. The input frequency used was $100 \mathrm{KHz}$. The voltage measurements taken at each stage were only measured at $100 \mathrm{KHz}$. The frequency response was found by varying the frequency from $10 \mathrm{KHz}$ to $300 \mathrm{KHz}$ and recording the voltage at the output of the circuit. The measured values at $100 \mathrm{KHz}$ are presented in TABLE II. A graph of the frequency response is shown in FIGURE 12 .

The gain of the two common source stages was designed to be 10. Due to the fact that the $g_{m}$ of each transistor may be from 1000-4000 us, the calculated gain is not exact. A gain higher than predicted is not detrimental, thus the gains of 15 and 11 for the two stages were acceptable. 


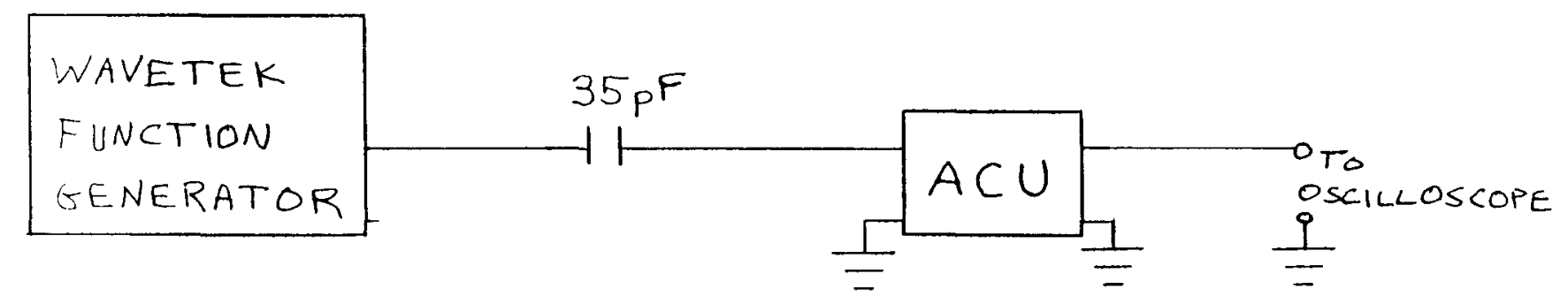

FIGURE 10 - Test Set-Up 

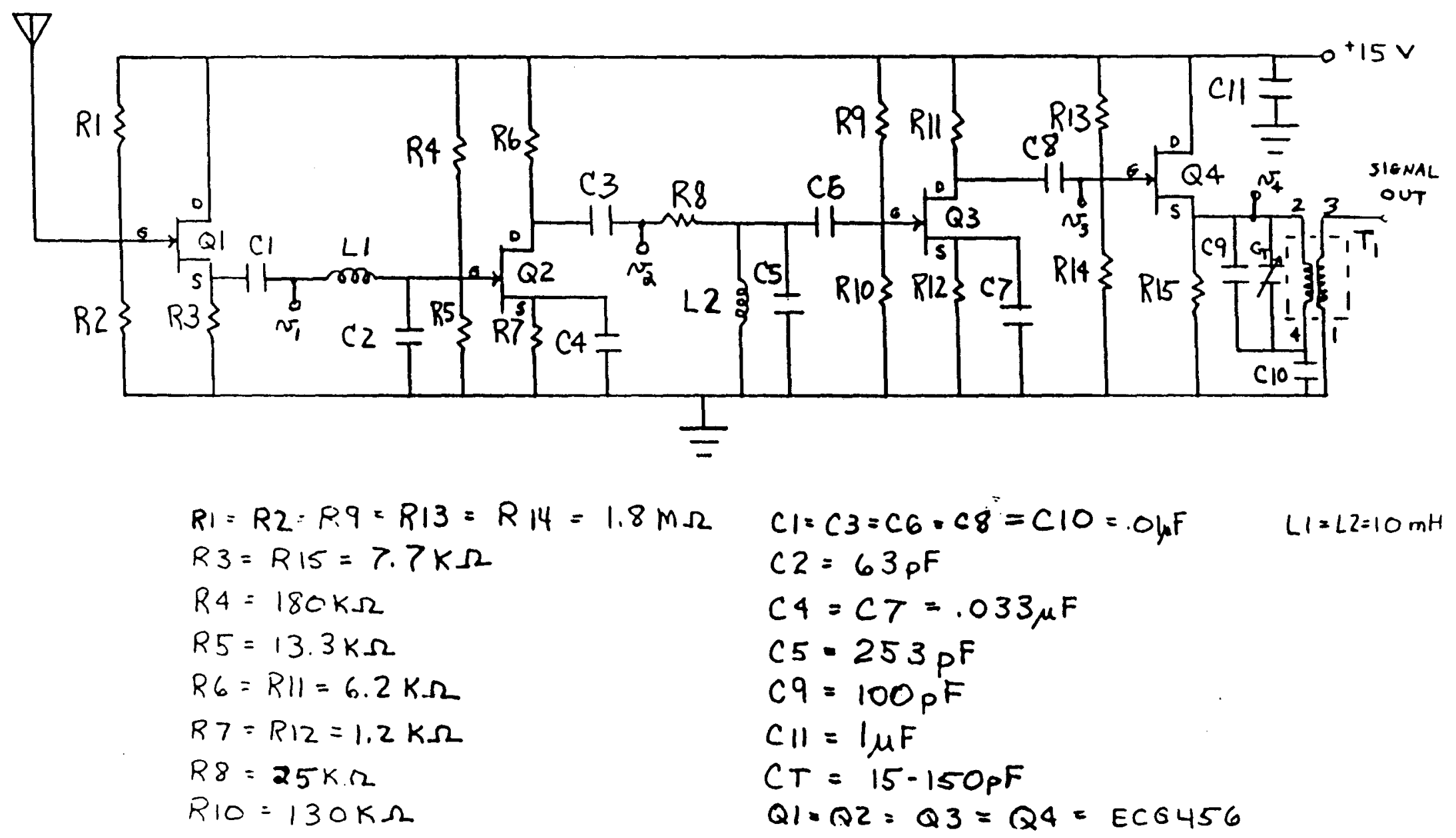
TABLE I I

AC MEASUREMENTS

\begin{tabular}{|c|c|}
\hline TP & VOLTAGE (mV) \\
\hline$v i$ & 10 \\
$v 1$ & 10 \\
$v 2$ & 150 \\
$v 3$ & 1700 \\
$V 4$ & 1650 \\
$V T$ & 400 \\
\hline
\end{tabular}




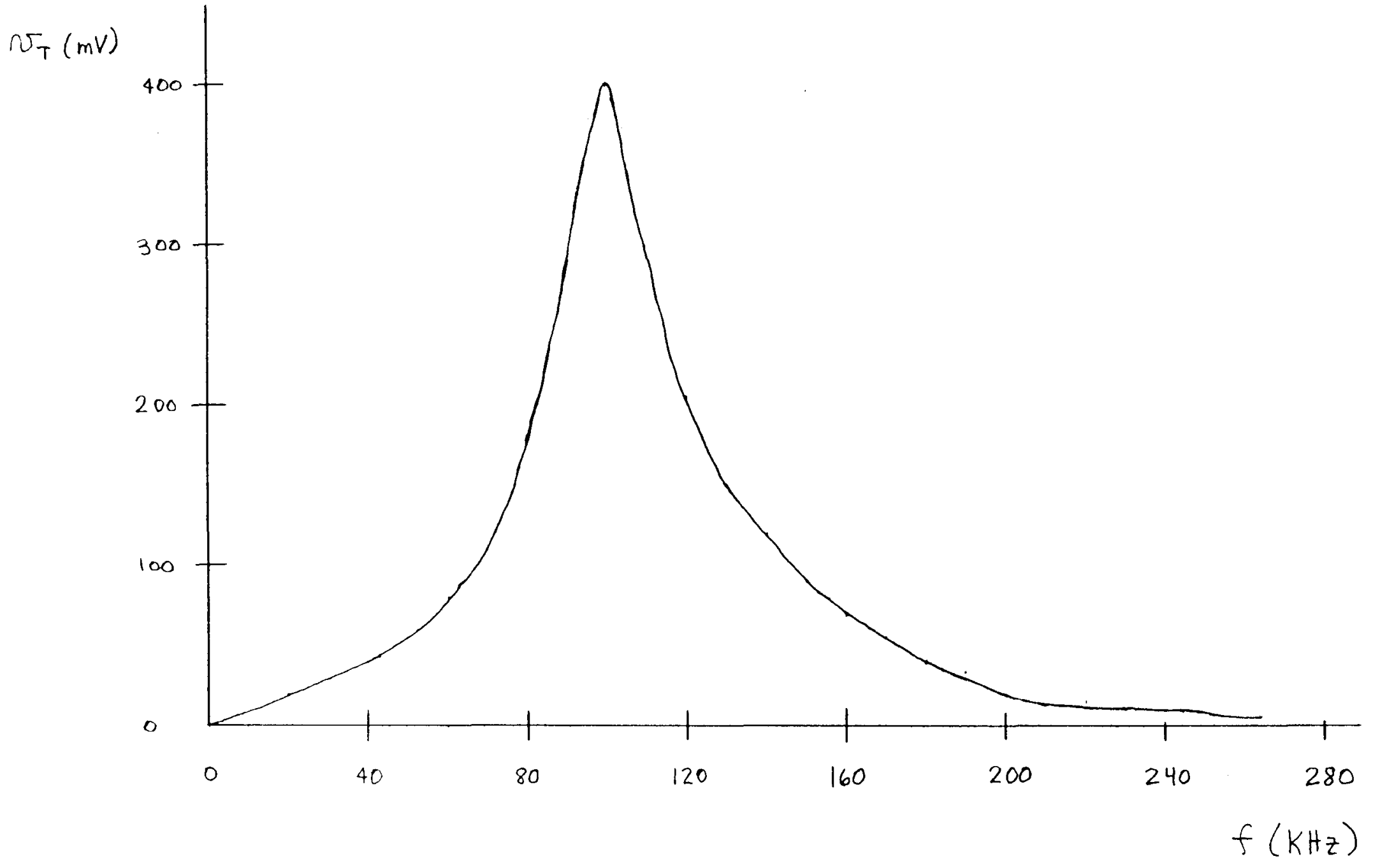

FIGURE 12 - Frequency Response of ACU 


\section{EQUIPMENT OPERATION AND DESCRIPTION}

\section{A. LORAN-C Receiver Operation}

When taking measurements with the LORAN-C receiver, time displacements (TD) and signal to noise ratios (SNR) are measured. To enable the receiver to display the TD, the following procedure is used:

1. Turn power on.

2. Press CLR. This clears the display.

3. Enter GRI, or Group Repetition Interval, by pressing GRI, then the 4 digit number representing the particular GRI desired, then press ENT. The numbers should flash to indicate the GRI was entered correctly.

4. Press AUTO. The receiver automatically displays up to four TD's (or stations) as they are received.

Until the station has locked in, the CYC light on the display will be 1 it. When the station is locked in, the CYC light will go off, and the numbers in the display are valid. If the CYC light is lit, the LORAN-C TD is not valid. The display will contain a number one through four as the first digit on the display. This is the number of the station. This is a number arbitrarily assigned by the unit to each TD. It is used to distinguish between or identify TDs when information or control over a particular TD is desired. A 
zero station number indicates the master station and numbers one through four represent the secondary station numbers associated with the displayed TD. The numbers following the station number represent the desired TDs. The TDs are displayed in microseconds in a five-digit readout followed by a decimal point and a sixth digit that indicates tenths of microseconds.

To obtain the SNR, the following procedure is used:

1. Press MON. This puts the unit in monitor operation.

2. Press the number of the station that is desired to obtain SNR; one through four for the secondaries and zero for the master.

3. Press 1. This is the monitor code to display SNR.

4. Press ENT.

The display now shows the station number and a three digit SNR number. The relationship between the SNR number and actual signal-to-noise ratio of the station can be seen in FIGURE 13.

\section{B. Additional Equipment}

Two differrent test set-ups were used. One set-up was located at the University of Louisville inside a building and the other was in a van of a professor at $U$ of $L$. The set-up at $U$ of $L$ consisted of a Hewlett-Packard Harrison 6291 A DC power supply, and the LORAN-C receiver. 


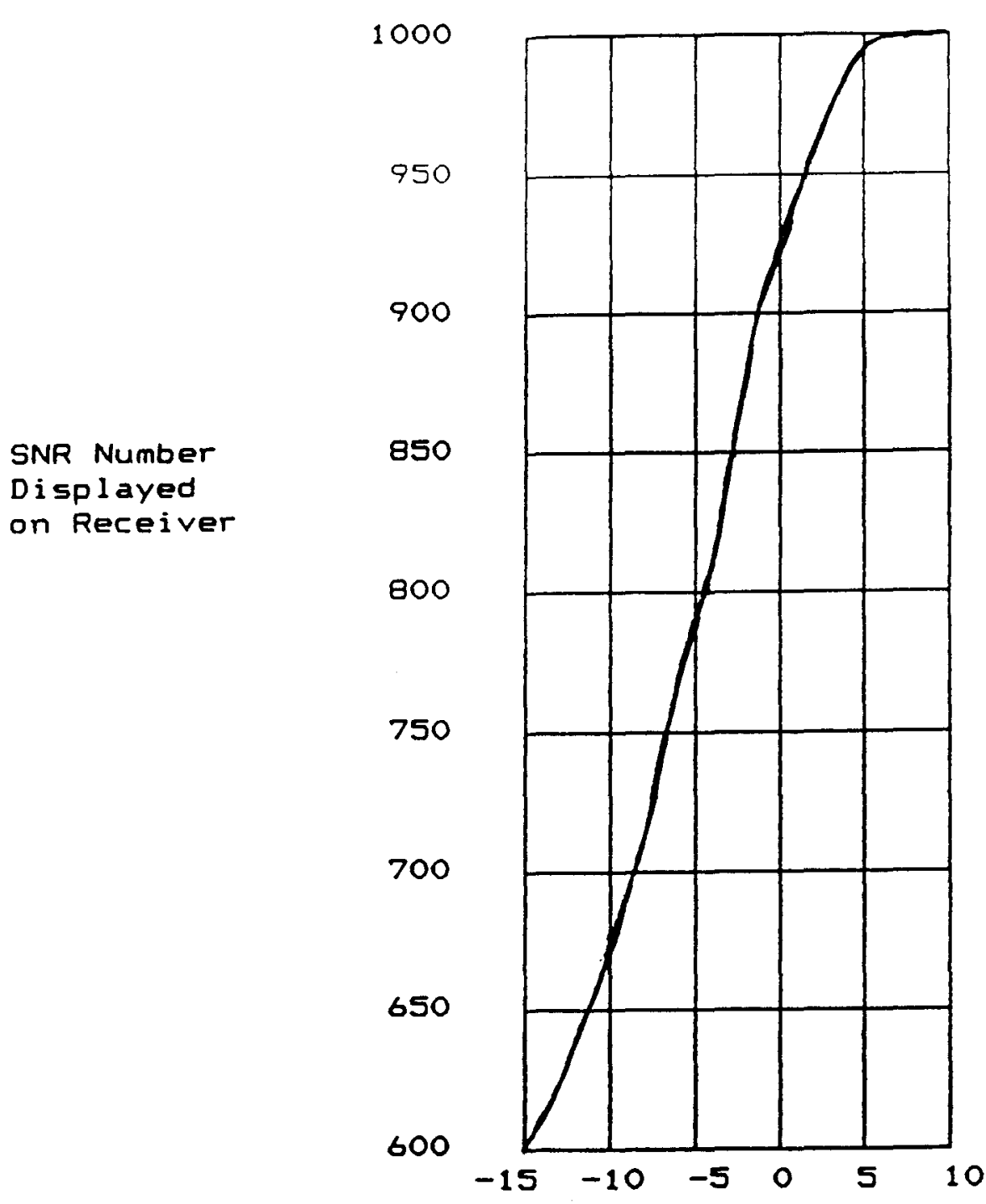

Actual Signal-to-Noise Ratio ( $d B$ )

FIGURE 13 - Signal-To-Noise Ratio Versus SRN Number ${ }^{7}$ 
The power supply provided the necessary DC voltage to operate the LORAN-C receiver. The power supply can put out 0 - 40 Volts at 0 - 5 Amps. This supply was ideal as the TI receiver needs 11 to 16 volts to operate. The receiver also draws about one and one-half amps when in use. An oscilloscope and a voltmeter were used by the author.

The equipment used in the van was the LORAN-C receiver and the battery of the van. A set of leads connected to the battery was available inside of the van and was connected to the LORAN-C receiver as the power supply. Both set-ups used the two ACUs, their cables, and their mounts. 


\section{RESULTS OF TESTING}

When testing the newly designed ACU, it was necessary to compare its operation with that of the TI ACU. Therefore the results of the testing will show measurements using the TI ACU and the ACU designed for this project.

The results presented here were obtained after first testing the ACU when it was out of tune. The first testing with the receiver was done when the ACU was tuned to $93 \mathrm{KHz}$. The results of this testing are shown in TABLE III. This slight de-tuning was thought to be very detrimental to the optimum performance of the ACU. Since the center frequency can be raised by lowering the capacitance, the capacitor C5 was lowered from $253 \mathrm{pF}$ to $220 \mathrm{pF}$. This is the capacitor in the band pass filter and had the most effect on the center frequency, $w_{0}$. By making this slight change, the author raised the center frequency to very nearly $100 \mathrm{KHz}$. The following testing was then done.

\section{A. Testing with a Radiating Antenna}

The first test performed showed the frequency response of the two units. This was done by radiating a sine wave near the antenna and the respective ACUs, then measuring the response over frequency of each unit. The voltage measurement taken was at test point E6 on the LORAN-C receiver. A wire was soldered to this point and 
TABLE I I I

DATA WITH ACU OUT OF TUNE

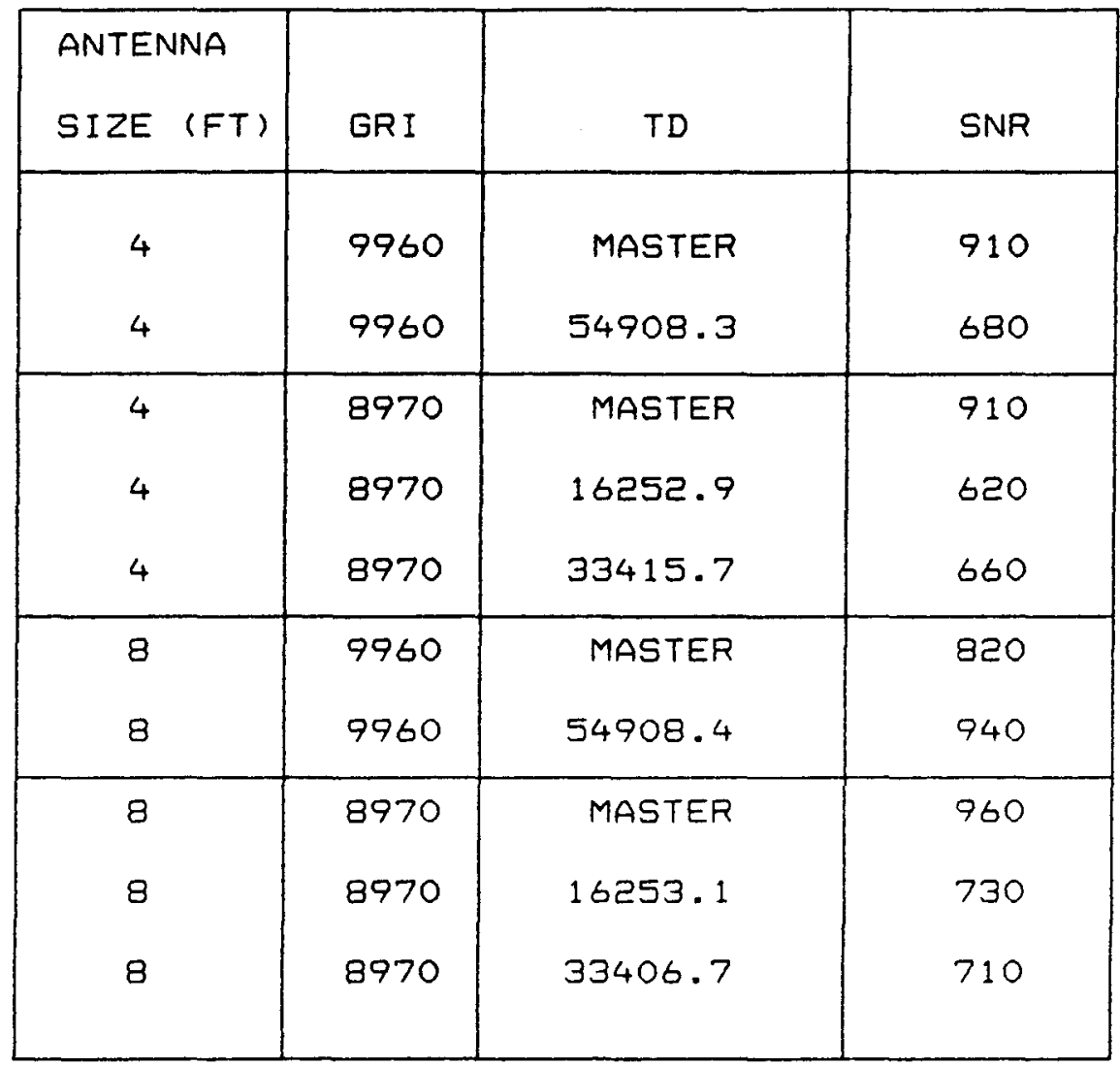


brought outside of the casing on the receiver. This point, E6, is directly before the RF amplifier on the TI LORAN-C receiver.

To perform this test, the author connected a piece of wire to a cable from the output of a Wavetek function generator. The wire was rigid and stood upright so that the signal could radiate from the wire. The generator put out enough voltage so that the receiving antenna could pick up the signal emanating from the piece of wire. The receiving antenna and ACU were placed two feet away from the transmitting antenna. The receiving antenna was a four-foot antenna. A frequency counter was also connected to the output of the function generator to monitor accurately the frequency of the radiating signal. The frequency was varied from $60 \mathrm{KHz}$ to $160 \mathrm{KHz}$.

The distance between the transmitting and receiving antennas was not changed for the two ACUs; therefore, the signal level into each ACU should have been the same. This value was not measured since the purpose of this test was to compare the two units. The values presented in TABLE IV are the voltages measured at test point E6. The graphs in FIGURES 14 and 15 show the frequency responses of the two ACUs.

\section{B. Testing With LORAN-C Receiver}

The testing of the ACU with the LORAN-C receiver was done at the University of Louisville (U of $L$ ) and a public park approximately four miles from $U$ of $L$. The preliminary 
TABLE IV

DATA WITH RADIATING ANTENNA

\begin{tabular}{|c|c|c|}
\hline FREQ. $\quad(K H z)$ & $\begin{array}{l}\text { VOLTAGE AT EG } \\
\text { WITH ACU }(m \mathrm{~m})\end{array}$ & $\begin{array}{l}\text { VOLTAGE AT EG } \\
\text { WITH TI ACU }(\mathrm{mV})\end{array}$ \\
\hline 60 & $<5$ & $<5$ \\
\hline 65 & $<5$ & $<5$ \\
\hline 70 & $<5$ & $<5$ \\
\hline 75 & 20 & 10 \\
\hline 80 & 65 & 20 \\
\hline 85 & 190 & 55 \\
\hline 90 & 400 & 100 \\
\hline 95 & 600 & 140 \\
\hline 100 & 700 & 155 \\
\hline 105 & 640 & 160 \\
\hline 110 & 460 & 130 \\
\hline 115 & 230 & 70 \\
\hline 120 & 100 & 30 \\
\hline 125 & 40 & 20 \\
\hline 130 & 20 & 10 \\
\hline 140 & 10 & 10 \\
\hline
\end{tabular}




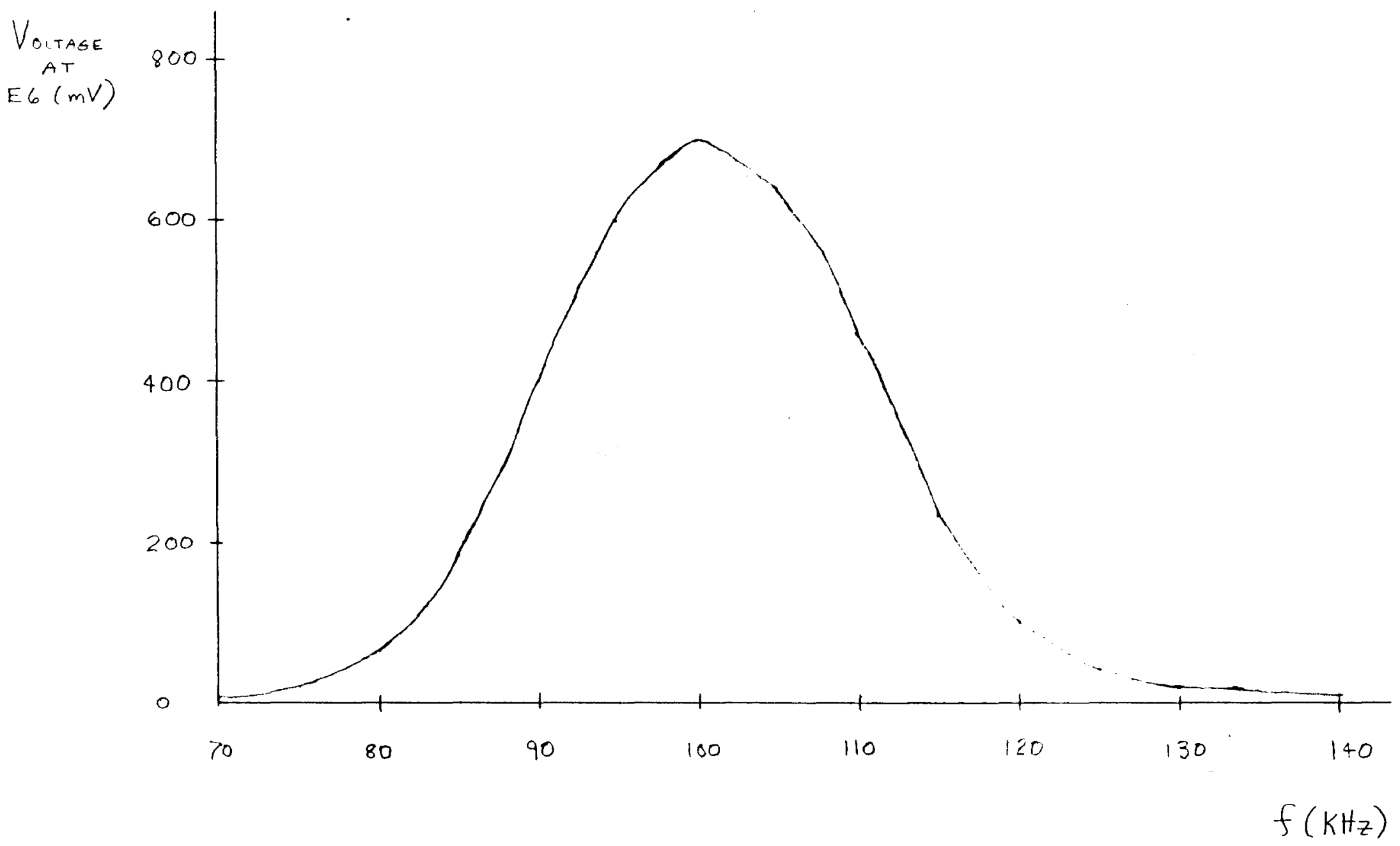

FIGURE 14 - Frequency Response of ACU

\& 


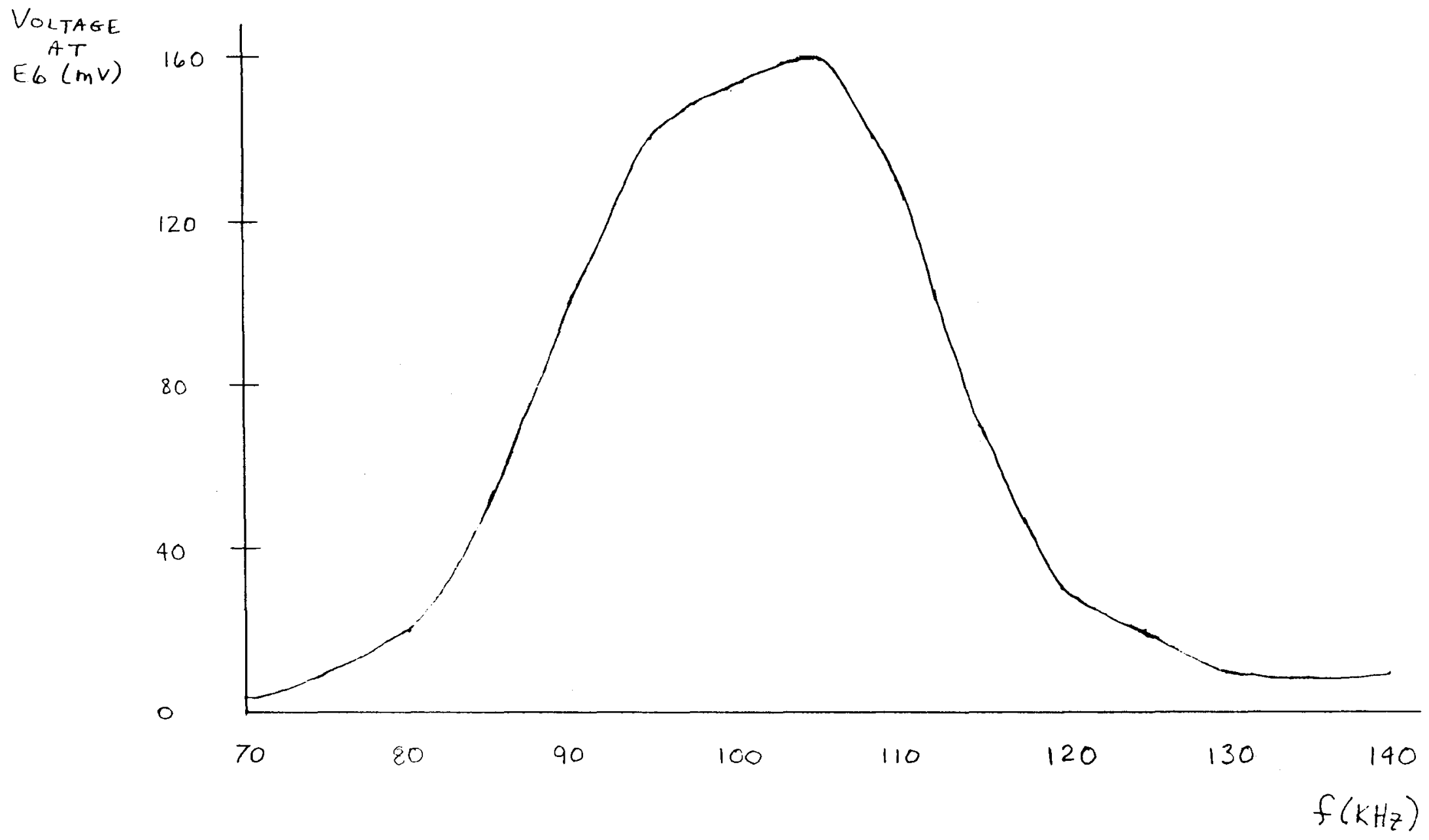

FIGURE 15 - Frequency Response of TI ACU

क 
testing was done at $U$ of $L$ with the test equipment described in Chapter VI. Additional testing was done at $U$ of $L$ and the public park in the van also described in Chapter VI. The preliminary testing was done by using a fourfoot antenna and an eight-foot antenna. The 28 " antenna was not available for the preliminary testing. The antenna and ACU were placed on a piece of sheet metal (for a ground plane) and placed on the ground in a field about 15 yards from the building containing the receiver. The four-foot and eight-foot antennas were used with the ACU and the TI ACU. The four-foot antenna was placed with the ACU, and time displacements (TDS) and signal-to-noise ratio (SNR) for each station were recorded for two differrent chains ("Chains" are the GRIs used, 8970 or 9960). The same was done using the eight-foot antenna. This process was also performed using the TI ACU. The data acquired is presented in TABLES $V$ and $V I$.

Data was taken on the four- and eight-foot antennas to determine if the circuit worked comparably to the TI ACU, which it did. After determining this, the author took the unit out on a different field test.

The next field test was done with the LORAN-C receiver inside a van and the 28-inch antenna and ACU on the roof of the van. The eight-foot antenna was mounted on the bumper of the van along with the TI ACU. For this testing, data was taken at two locations.

First, the van was driven to a public park and 
TABLE $V$

DATA WITH ACU

\begin{tabular}{|c|c|c|c|}
\hline $\begin{array}{l}\text { ANTENNA } \\
\text { SIZE (FT) }\end{array}$ & GR I & TD & SNR \\
\hline 4 & 9960 & MASTER & 850 \\
\hline 4 & 9960 & 54918.3 & 950 \\
\hline 4 & 9960 & 42007.8 & 730 \\
\hline 4 & 8970 & MASTER & 950 \\
\hline 4 & 8970 & 16252.9 & 880 \\
\hline 4 & 8970 & 33406.1 & 870 \\
\hline 4 & 8970 & 51495.5 & 600 \\
\hline 8 & 9960 & MASTER & 900 \\
\hline 8 & 9.960 & 28591.2 & 660 \\
\hline 8 & 9960 & 42007.9 & 800 \\
\hline 8 & 9960 & 54918.2 & 950 \\
\hline 8 & 8970 & MASTER & 960 \\
\hline 8 & 8970 & 15252.9 & 905 \\
\hline 8 & 8970 & 33406.1 & 875 \\
\hline 8 & 8970 & 51495.5 & 670 \\
\hline
\end{tabular}


TABLE VI

DATA WITH TI ACU

\begin{tabular}{|c|c|c|c|}
\hline $\begin{array}{l}\text { ANTENNA } \\
\text { SIZE (FT) }\end{array}$ & GR I & $T D$ & SNR \\
\hline 4 & 9960 & MASTER & 870 \\
\hline 4 & 9960 & 54918.5 & 930 \\
\hline 4 & 9960 & 42008.0 & 770 \\
\hline 4 & 8970 & MASTER & 955 \\
\hline 4 & 8970 & 16253.1 & 890 \\
\hline 4 & 8970 & 33406.1 & 860 \\
\hline 4 & 8970 & 51495.3 & 630 \\
\hline 8 & 9960 & MASTER & 900 \\
\hline 8 & 9960 & 28590.9 & 680 \\
\hline 8 & 9960 & 42008.1 & 850 \\
\hline 8 & 9960 & 54918.2 & 950 \\
\hline 8 & 8970 & MASTER & 960 \\
\hline 8 & 8970 & 16252.9 & 905 \\
\hline 8 & 8970 & 33406.1 & 900 \\
\hline 8 & 8970 & 51495.5 & 720 \\
\hline
\end{tabular}


measurements were made using the 28-inch antenna. This data was taken for two different chains, 8970 and 9960 . The data taken on the TI LORAN-C ACU was acquired by using the eightfoot antenna on the two different chains.

The van was then driven to the University of Louisville. The 28-inch antenna was used with the ACU and the eight-foot antenna was used with the TI ACU. The data was taken again on chains 8970 and 9960 . The data obtained at the park and at $U$ of $L$ are presented in TABLES VII and VIII.

The final test was the placing of the ACU on the roof of the van with the 28-inch antenna and recording the TDs and SNRs on chain 9960. The TI ACU was then placed on the roof with the 28 -inch antenna. This test was done to view the operation of the ACUs when they are at the same level. The results are presented in TABLE IX. 
TABLE VII

DATA WITH 28 INCH ANTENNA AND ACU (IN VAN)

\begin{tabular}{|c|c|c|c|}
\hline LOCATION & GRI & TD & SNR \\
\hline PARK & 9960 & MASTER & 821 \\
PARK & 9960 & 42008.0 & 702 \\
PARK & 9960 & 54930.9 & 969 \\
PARK & 8970 & MASTER & 975 \\
PARK & 8970 & 16247.7 & 820 \\
PARK & 8970 & 33393.3 & 830 \\
PARK & 8970 & 51494.3 & 640 \\
\hline U of $L$ & 9960 & MASTER & 890 \\
U of $L$ & 9960 & 42007.4 & 760 \\
U of $L$ & 9960 & 54917.9 & 970 \\
$U$ of $L$ & 8970 & MASTER & 970 \\
U of $L$ & 8970 & 16252.0 & 900 \\
U of $L$ & 8970 & 33406.4 & 890 \\
U of $L$ & 8970 & 51495.6 & 700 \\
\hline
\end{tabular}


TABLE VIII

DATA WITH EIGHT FOOT ANTENNA AND TI ACU (IN VAN)

\begin{tabular}{|c|c|c|c|}
\hline LOCATION & GRI & TD & SNR \\
\hline PARK & 9960 & MASTER & 950 \\
PARK & 9960 & 28589.8 & 830 \\
PARK & 9960 & 42008.2 & 900 \\
PARK & 9960 & 54931.0 & 960 \\
PARK & 8970 & MASTER & 978 \\
PARK & 8970 & 16247.7 & 930 \\
PARK & 8970 & 33393.3 & 940 \\
PARK & 8970 & 51494.1 & 928 \\
\hline U of $L$ & 9960 & MASTER & 950 \\
U of $L$ & 9960 & 28591.4 & 840 \\
U of $L$ & 9960 & 42007.4 & 910 \\
U of $L$ & 9960 & 54917.8 & 965 \\
U of $L$ & 8970 & MASTER & 970 \\
U of $L$ & 8970 & 16252.1 & 940 \\
U of $L$ & 8970 & 33406.4 & 940 \\
U of $L$ & 8970 & 51495.6 & 920 \\
\hline
\end{tabular}


TABLE IX

DATA WITH BOTH ACUS AND 28 INCH ANTENNA

\begin{tabular}{|l|l|c|l|}
\hline UNIT & GRI & TD & SNR \\
\hline ACU & 9960 & MASTER & 900 \\
ACU & 9960 & 42007.2 & 770 \\
ACU & 9960 & 54917.7 & 965 \\
\hline TI ACU & 9960 & MASTER & 940 \\
TI ACU & 9960 & 28591.3 & 795 \\
TI ACU & 9960 & 42007.3 & 910 \\
TI ACU & 9960 & 54917.7 & 970 \\
\hline
\end{tabular}




\section{DISCUSSION OF RESULTS}

The data presented in Chapter VII, section A, was obtained by radiating a $100 \mathrm{KHz}$ signal in the vicinity of a four-foot antenna that was connected to each ACU. This test was to determine the bandpass and relative gain of each ACU. By finding the $3 \mathrm{~dB}$ points of each $\mathrm{ACU}$, the bandpass was determined. The bandpass for the ACU was found to be $92 \mathrm{KHz}$ - $109 \mathrm{KHz}$ with the maximum magnitude occurring at $100 \mathrm{KHz}$. The bandpass of the TI ACU was found to be $91 \mathrm{KHz}-112 \mathrm{KHz}$ with the maximum magnitude occurring at $105 \mathrm{KHz}$. The bandpass of the ACU was determined in Chapter $V$ to be $89 \mathrm{KHz}$ to $112 \mathrm{KHz}$ with a peak at $100 \mathrm{KHz}$. There seemed to be a contradiction, but the two sets of measurements were taken differently. The voltage reading measured with the radiating antenna was taken at test point E6 in the LORAN-C receiver. Therefore, not only did the signal pass through the ACU, but also through a tuned transformer at the front end of the receiver. This additional filtering performed by the transformer narrows the bandpass slightly and attenuates frequencies outside of the pass band more efficiently.

The gains of the two ACUs cannot be determined by this testing since the input level is unknown. But, a comparison of the two can be obtained. At the carrier frequency of $100 \mathrm{KHz}$, the $\mathrm{ACU}$ has four and one half times more gain than that of the TI ACU. Therefore, since the 
received signal strength is directly proportional to antenna height, by reducing the antenna to 28 inches $(3.4$ times less than the original), a gain of 4.5 times the original should be sufficient. This is certainly not the only determining factor in achieving an ACU that functions the same with the 28 inch antenna. Many other factors make the gain factor somewhat trivial.

The remainder of the data presented in the previous chapter was obtained by use of the LORAN-C receiver as it functions in the field. This testing was done to see if the ACU could pick LORAN-C stations and compare its receiving capability to that of the TI ACU.

Before the comparison of the ACUs, there will be a brief discussion of the importance of tuning the ACU. The data in TABLE III shows the TDs (or stations) received and their corresponding SNR numbers with the ACU out of tune. By comparing the data of TABLE III with that of TABLE $V$, which is with the ACU tuned to $100 \mathrm{KHz}$, the vast improvement can be seen. With the ACU tuned, more stations were received accurately, and of those stations received with the ACU de-tuned and tuned, the SNR numbers were better. A couple of the TDs were even off by 10 us, which can be attributed to the de-tuned ACU. This reveals that even a slight de-tuning of the ACU (7 KHz, or less than $10 \%)$, is very detrimental to the proper operation of the ACU and the receiver.

The data in TABLES $V$ and VI were taken on the same 
day with identical conditions. The main item of interest in the tables is the SNR number. The TDs are very close to identical and only reveal that the ACU does not affect the determination of the TDS. The SNR numbers, on the other hand, are slightly different. The SNR numbers of the ACU are generally about 20 - 30 less than the TI ACU. The lower SNR shows that the ACU does not function as well as the TI $A C U$, but functions very nearly as well.

The data in TABLES VII, VIII, and IX reinforce the inferiority of the ACU. With the 28-inch antenna in use with the ACU, the number of stations received is less and the SNR of the received stations is also less. The ACU did receive well on the 8970 chain with only slightly lower SNR numbers for two of the three stations. The master was received just as well but the secondaries were not. The ACU with the 28-inch antenna does not affect the function of determining the TDs. Every TD received when the ACU was in use was identical to the TD achieved with the TI ACU in use. The data in TABLE IX was obtained with both ACUs using the 28-inch antenna. With the units being tested in the same position, the ACU performed better. The TI ACU is about eight inches in length and stands upright when in use. This raised the antenna and made the testing of the two units not exactly identical. This is the only difference in set-ups and could possibly have had an effect on the performance of the TI ACU. The ACU did receive two stations and the master. One of the stations was received just as well, one 
was received with a severe difference in the SNR, and the station 28591.3 was not even picked up by the ACU. The additional height added by the TI ACU is one possible reason it performed better than the ACU. Other possible reasons are discussed in CONCLUSIONS. Also discussed are some additions that could have enhanced the performance of the ACU . 


\section{CONCLUSIONS}

After the final test was performed on the ACU, it was concluded that the ACU did not function so well as the TI ACU. In order to try to get the signal-to-noise ratio up, a tuned, parallel RLC circuit was added at the input to the ACU circuitry. The RLC circuit was designed to have a bandpass of $40-50 \mathrm{KHz}$ and have a center frequency of $100 \mathrm{KHz}$. It was believed that if some filtering was performed at the front end, the noise outside of the pass band would be reduced. The noise eliminated at the front end would also not be amplified.

The RLC circuit was added and the ACU was tested with the LORAN-C receiver in the van. The result is that the receiver would not receive any stations at all. Since it was difficult to determine the effects of the antenna on the RLC circuit, the antenna, along with the RLC circuit, may have de-tuned the circuit. If this was the case, then the ACU would obviously not function properly. Another possible reason that the RLC circuit degraded the operation of the ACU was because it may put the LORAN signal very far out of phase. The TI LORAN-C receiver analyzes certain points of the incoming signal for information. If these points are shifted too far, the receiver will not function, or will function poorly at best. After trying to add the RLC circuit and obtaining poor results, it was decided that 
additional work on this project would be done in the future. One possible reason that the ACU did not function as desired is because of the fact that the transistors used were not low noise. When the research was being done for this project, the transistor chosen was the Motorola 2N4220. This FET was low-noise and useful for the frequency of $100 \mathrm{kHz}$. When the order was placed at a local electronics supplier, the Motorola part was requested. A replacement was given since the 2 N4220 was not available. This was the ECG456. It was assumed that this was a good replacement for the low-noise Motorola FET. This assumption was wrong. It was not until after the project was nearly complete that it was realized that the ECG456 was a general purpose FET. The pin-out of the transistor was the same and that was probably the main thing with which people at the electronics supplier were concerned. The Motorola parts were finally obtained but many changes in the design would have been necessary. They were inserted in place of the ECG456 FETs, but the'DC voltages were affected drastically.. This is why it was decided that too many design changes would have been necessary. If the transistors used had been low-noise, it is felt that the SNR would have been higher.

Another problem with the transistors used was that the $V_{p}$ and $I_{d s s}$ were found to be different than the specifications given for the $2 \mathrm{~N} 4220$. This is part of the reason the desired DC values and measured DC values shown in TABLE I were different. 
An FET amplifier has a wide range of operation. As long as the value of $V_{d s}$ does not correspond to a point in the linear region of the $I_{d s}$ vs. $V_{d s}$ curves, the amplifier will function properly. Even though the measured DC values shown in TABLE I differ in some cases from the desired values, $V_{d s}$ does not go into the 1 inear region for this design. Therefore, the ACU functions properly.

Another possible solution to reducing the noise in the ACU would have been to make the PC board differently. The one used was single-sided with as much ground plane as possible on the etched side. If the other side of the board had been one big ground plane, a reduction in noise could have resulted.

The last possible source of the low SNR is that the receiver and the ACU may have been mismatched. While the impedance matching transformer worked for the TI application, it may not be exactly right in this application. But, since there is really no good way to measure input and output impedances with any of the equipment available at $U$ of $L$, the use of the transformer seemed to be the best solution. If it had been possible to determine the input impedance of the TI LORAN-C receiver, a transformer could have been wound and a good match obtained. It is believed that the $A C U$ and receiver were mismatched thus adding to the low SNR obtained for some of the stations.

While this project was not totally successful so far 
as meeting preliminary specifications is concerned, a tremendous amount was learned and a fairly good working unit was obtained. Had equipment such as a network analyzer and spectrum analyzer been available, it is felt a better job could have been accomplished on this project. 


\section{REFERENCES}

1. McKenzie, A.A., Pierce, J.A., and Woodward, R.H., LORAN, McGraw-Hill, New York, 1948, p. 62.

2. U.S. Department of Transportation, Interference and Noise in and Adjacent to the LORAN-C Spectrum at Airports, Cambridge, Massachusetts, 1975, p. 1-1.

3. Van Der Wal, Peter W. and Van Willigen, Durk, "Hard Limiting and Sequential Detection Applied to LORAN-C", IEEE Transactions on Aerospace and Electronic Systems, Vol. AES-14, No. 4 (July 1978), pp 649-661.

4. Ibid.

5. Boylestad, Robert and Nashelsky, Louis, Electronic Devices and Circuit Theory, Prentice-Hall, Englewood Cliffs, New Jersey, 1982, p. 192.

6. Teledyne Systems Co., Depot Repair Documentation LORAN-C 708 Receiver, Part Number 8014505-507, 1973, p. 2-I.

7. Texas Instruments, Inc., TI 9000 Series LORAN-C Receivers Service Manual, Manual Part Number 2056639-1, 1978, p. 


\section{BIBLIOGRAPHY}

Boylestad, Robert and Nashelsky, Louis, Electronic Devices and Circuit Theory, Prentice-Hall, Englewood Cliffs, New Jersey, 1982 .

Budak, A., Passive and Active Network Analysis and Synthesis, lst ed., Houghton Mifflin, 1974 .

McKenzie, A.A., Pierce, J.A., and Woodward, R.H., LORAN, McGraw-Hill, New York, 1948.

Teledyne Systems Co., Depot Repair Documentation LORAN-C 708 Receiver, Part Number 8014505-507, 1973 .

Texas Instruments, Inc., TI 9000 Series LORAN-C Receivers Service Manual, Manual part number 2056639-1, 1978.

U.S. Department of Transportation, Interference and Noise in and Adjacent to the LORAN-C Spectrum at Airports, Cambridge, Massachusetts, 1975.

Van Der Wal, Peter W. and Van Willigen, Durk, "Hard Limiting and Sequential Detection Applied to LORAN-C", IEEE Transactions on Aerospace and Electronic Systems, Vol. AES-I4, No. 4 (July 1978). 
VITA

Timothy Andrew Reilly, the son of John David and Evelyn Zehnder Reilly, was born on June 18, 1963, in Louisville, Kentucky. The author graduated from saint Xavier High School in May, 1981, and enrolled in the speed Scientific School of the University of Louisville in August, 1981

While studying electrical engineering at speed Scientific school, the author served three cooperative internships at Motorola, Inc., in Fort Lauderdale, Florida. He also became a member of the Institute of Electrical and Electronics Engineers (IEEE), Eta Kappa Nu, and Tau Beta Pi (national engineering honor societies). He received his Bachelor of Science degree in May, 1986. During his graduate year, he served as president of the IEEE Student Branch. In May, 1986, he received the $M$. Gordon Northrop Award from the Louisville Section of the IEEE. He received his Master of Engineering degree, with Specialization in Electrical Engineering, from the University of Louisville in December, 1986. 